\title{
LA MILPA COMEDERO-TRAMPA COMO UNA ESTRATEGIA DE CACERÍA TRADICIONAL MAYA
}

\author{
DíDAC SANTOS-Fita \\ Centro Regional de Investigaciones Multidisciplinarias, UNAM \\ Departamento de Conservación de la Biodiversidad, \\ El Colegio de la Frontera Sur, Unidad San Cristóbal
}

\author{
Eduardo J. Naranjo Piñera \\ Eduardo Bello Baltazar \\ ERIN I. J. ESTRADA LUGO \\ RAMÓN MARIACA MÉNDEZ \\ El Colegio de la Frontera Sur, Unidad San Cristóbal \\ Pedro A. Macario Mendoza \\ El Colegio de la Frontera Sur, Unidad Chetumal
}

\begin{abstract}
Resumen: Los mayas conciben la cacería como una práctica integrada al resto de las actividades dentro de su sistema productivo. En el presente estudio resaltamos el uso que hacen de la agricultura de roza-tumba-quema para cazar. Se describe y delimita la que hemos denominado como "milpa comedero-trampa": práctica de manejo del hábitat donde la siembra de cultivos agrícolas interesa exclusivamente para atraer y cazar determinadas especies de vertebrados terrestres, no para obtener cosechas para autoconsumo. Se caracterizan los componentes técnicos y la organización social involucrada que identifican a esta variante o subsistema de milpa, como su reducido tamaño (entre 1-3 mecates), la ausencia de la fase de quema o que ésta es microlocalizada, que el maíz (Zea mays) no es el cultivo primordial, o que la milpa es de carácter enteramente individual, entre otros. En una milpa comedero-trampa, la agricultura y la cacería constituyen un nexo tecnológico para obtener presas en un espacio muy especializado dentro del territorio (que no es la típica ix kool o, como la llamaremos aquí, milpa convencional).
\end{abstract}

Palabras clave: cacería, milpa, manejo del hábitat, cultura maya, Península de Yucatán.

ABSTRACT: The Maya conceive hunting as an integrated activity within their productive system. In this study, we draw attention to the use of slash-and-burn agriculture to capture wild fauna. The milpa comedero-trampa (the "milpa trough-trap"), as we have named it, is described and delimited as a habitat management practice in which cultivating is only done to enable hunting, and not to obtain cultivated products. The technical components and social organization involved in this variant or subsystem of the milpa are characterized, including its reduced size (1-3 mecates), the absence of burning or its restriction, the secondary role of Zea mays, or their individual nature. In a milpa comedero-trampa agriculture and hunting form a technological link to obtain prey in a specialized space (different from the conventional ix kool or milpa convencional, as it is referred to here).

KeYwords: hunting, milpa, habitat Management, Mayan culture, Yucatan Peninsula.

RECEPCIÓN: 15 de noviembre de 2012.

ACEPTACIÓN: 28 de febrero de 2013. 



\title{
LA MILPA COMEDERO-TRAMPA COMO UNA ESTRATEGIA DE CACERÍA TRADICIONAL MAYA
}

\author{
Dídac Santos-Fita \\ Centro Regional de Investigaciones Multidisciplinarias, UNAM \\ Departamento de Conservación de la Biodiversidad, \\ El Colegio de la Frontera Sur, Unidad San Cristóbal \\ Eduardo J. Naranjo Piñera \\ Eduardo Bello Baltazar \\ ERIN I. J. ESTRADA LUGO \\ Ramón Mariaca MÉndez \\ El Colegio de la Frontera Sur, Unidad San Cristóbal \\ Pedro A. Macario Mendoza \\ El Colegio de la Frontera Sur, Unidad Chetumal
}

\section{Introducción}

Comunidades mayas ${ }^{1}$ adoptan prácticas de uso y manejo de animales silvestres para múltiples propósitos, mediante su cacería o captura viva, como parte esencial y significativa de su realidad y cotidianidad en contexto rural. Son varias las especies de vertebrados terrestres a destacar dentro de esta fauna, tales como los venados (cola blanca: Odocoileus virginianus, y temazate: Mazama spp.), los pecaríes (de collar: Pecari tajacu, y de labios blancos: Tayassu pecari), el tepezcuintle (Cuniculus paca), el armadillo (Dasypus novemcinctus), el tejón (Nasua narica), la tuza (Orthogeomys hispidus), los felinos (e.g., jaguar: Panthera onca, puma: Puma concolor, ocelote: Leopardus pardalis), aves de grande y mediano porte como el pavo de monte u ocelado (Meleagris ocellata, endémico de la Península de Yucatán), el faisán (Crax rubra) y la cojolita (Penelope purpurascens), las iguanas (verde: Iguana iguana, y rayada: Ctenosaura similis) y las tortugas (e.g., jicotea: Trachemys scripta), entre otras especies de mamíferos, aves y reptiles (Jorgenson, 1993; Montiel, Arias y Dickinson, 1999; Escamilla et al., 2000; Delfín-González y Chablé-Santos, 2004; Santos-Fita, Naranjo y Rangel-Salazar, 2012). De estas especies silvestres aún se obtiene carne - para consumo y como parte de la ofrenda en ceremonias propiciatorias-, grasa, productos medicinales, pieles, plumas, huesos y otras partes para distintos fines. También se utilizan como ornato, compañía (mascotas) o para la reducción de daños

\footnotetext{
${ }^{1}$ Se utiliza el término maya para referir al grupo etnolinguístico de los mayas yucatecos o peninsulares, es decir, habitantes de la Península de Yucatán, México.
} 
a cultivos y generación de pequeños ingresos económicos por venta de los excedentes de carne (según el tipo de presa) dentro de la misma comunidad o en núcleos urbanos próximos, pero sin mercados establecidos (Santos-Fita, Naranjo y Rangel-Salazar, 2012).

En dicho ámbito se cataloga como cacería de subsistencia al hecho de destinar los recursos faunísticos a satisfacer las necesidades básicas del cazador, así como de sus familiares y allegados (Bennett y Robinson, 2000), y ocasionalmente también las de toda la comunidad (Montiel, Arias y Dickinson, 1999; Santos-Fita, 2013). No obstante, al ser la cacería parte fundamental de la cultura de cada grupo social, no se la puede considerar como una simple actividad de subsistencia material, sino más bien "representa una manera de extraer recursos de la naturaleza que descansa en una amplia construcción a la vez social, simbólica y ritual" (Dehouve, 2008: 4). En otras palabras, los vínculos que los mayas contemporáneos establecen con la fauna silvestre y con el acto de cazar (en particular venado y pecarí) también ponen de manifiesto sus creencias y prácticas rituales - individuales o colectivas- y, por extensión, sus esquemas de representación y visión del mundo o cosmovisión (Villa Rojas, 1987: 294-296, 308, 319, 450; Bartolomé, 1988: 226-227; Llanes-Pasos, 1993; Terán y Rasmussen, 1994: 281-283; Santos-Fita, 2013), al igual como sucedía en la época prehispánica y el período colonial (Montolíu, 1976; RHGGY, 1983, vol. I: 286, vol. II: 226; Garza, 1984: 82-85; Landa, 1994: 151, 173-174 [1566]).

Aunado a lo anterior, los mayas conciben la cacería como una práctica integrada al resto de las actividades dentro de su sistema productivo y socioeconómico. Si bien se ha transformado con el paso del tiempo, este sistema aún gira en torno a determinadas prácticas agrícolas íntimamente ligadas a prácticas hortícolas, silvícolas y otros tipos de aprovechamiento del bosque tropical (Barrera-Marín, Gómez-Pompa y Vázquez-Yanes, 1977; Gómez-Pompa, 1987 y 2003; Fedick, 1996). Un uso y manejo múltiple de los ambientes selváticos —sus espacios, recursos abióticos y biodiversidad- favorece que se den simultáneamente diversas actividades en un mosaico de parches, incluyendo solares o huertos familiares, áreas agrícolas, selvas secundarias en distintos grados de sucesión por "descanso agrícola”, selvas maduras, sabanas y cuerpos de agua (Sanabria, 1986; Ramírez-Barajas et al., 2001; Toledo et al., 2008: 346-349; Bello y Estrada, 2011).

El sistema maya de producción agrícola bajo una agricultura de roza-tumbaquema (RTQ) en selvas secundarias, la milpa —en maya yucateco, ix kool-, constituye el eje central que articula toda la estrategia productiva y reproductiva de aprovechamiento y manejo integral de la selva. A su vez, las actividades no agrícolas también se interrelacionan en mayor o menor grado entre sí y con la milpa (Terán y Rasmussen, 1994; Ramírez-Barajas et al., 2001; Mariaca, González-Jácome y Arias, 2010: 20-25). Además de la cacería o captura de fauna silvestre, destacan las siguientes actividades: a) recolección de plantas silvestres usadas como alimento, sustancias medicinales, leña, inciensos y objetos ceremoniales, materiales para construcción, material para hornos de cal, y recientemente extracción maderable comercial (Barrera-Marín, Barrera-Vázquez y López-Franco, 1976; Anderson, 2003; 
Macario y Sánchez, 2011); b) diversas técnicas silvícolas² ${ }^{2}$ introducción, selección y protección de árboles con diversos usos (Barrera-Marín, Gómez-Pompa y Vázquez-Yanes, 1977; Gómez-Pompa, 1987); c) pesca (Ramírez-Barajas et al., 2001; Arce-Ibarra, 2007), y d) recolección de miel y cera: meliponicultura y apicultura (Porter-Bolland, 2003), entre otras. Estas actividades se articulan al ritmo de la actividad milpera. También está el solar o huerto familiar, visto como otro sistema agrícola y silvícola, así como espacio de domesticación y semidomesticación, pero a menor escala y aledaño a la casa-habitación o incluyéndola (Mariaca, GonzálezJácome y Arias, 2010: 31-58; Lope-Alzina y Howard, 2012).

Son escasos los estudios que específicamente se han centrado en el manejo que los mayas hacen de sus áreas agrícolas también como espacios para fines de cacería (Greenberg, 1992; Jorgenson, 1993; Saldivia, 1994). Al hecho de cazar en parcelas dedicadas a la agricultura se le conoce en el medio académico como garden hunting —que significa literalmente "cacería en jardines" o, mejor dicho, en áreas cultivadas o huertos-, desde que Linares (1976) propuso el término al teorizar por vez primera (aunque no propiamente sobre mayas) acerca de dicha estrategia de subsistencia. Para el continente americano, tanto estudios arqueológicos (Linares, 1976; Speth y Scott, 1989; Neusius, 1996; VanDerwarker, 2006) como etnográficos (Balée y Gély, 1989; Naughton-Treves, 2002; Smith, 2005) muestran que esta estrategia fue y sigue siendo una práctica frecuente entre grupos humanos en ambientes templados y, sobre todo, selváticos. Algunos autores (Neusius, 1996: 276; VanDerwarker, 2006: 148-151) incluso proponen nuevas interpretaciones al cuándo y porqué ocurre dicha "cacería en parcelas agrícolas" (comparado a la explicación inicial propuesta por Linares), esto es, qué tan selectiva u oportunista es en verdad la caza (si se prefieren o no determinadas presas) que transcurre en los espacios cultivados. Aunque sus respectivas conclusiones no pueden generalizarse a otros grupos indígenas y ecosistemas fuera de sus sitios de estudio (Linares, 1976; Neusius, 1996; VanDerwarker, 2006), enriquecen el campo teórico y de análisis para entender y delimitar el concepto de garden hunting y poder comparar esta práctica con otras estrategias de caza para fines de subsistencia.

En el presente estudio también se aborda el vínculo entre cacería y milpa, esto es, el uso de la agricultura de RTQ para cazar especies de fauna silvestre. No obstante, no nos centraremos específicamente en la ix kool o, como la llamaremos

\footnotetext{
${ }^{2}$ En la actualidad varias de estas prácticas y técnicas mayas tradicionales de manejo silvícola y sus conocimientos asociados, como el pet kot — vegetación útil cercada por un muro de piedra- o el t'olche' — cinturón de vegetación alrededor de las áreas de cultivo—, en general están en desuso (Gómez-Pompa, Flores y Sosa, 1987; Gómez-Pompa, 1987: 10; Remmers y Koeijer, 1992). Según los autores, una de las posibles funciones que podría haber tenido el pet kot era la de atraer y confinar animales silvestres de interés, a modo de semidomesticación. Semillas y frutos de ciertos árboles útiles, sobre todo del ramón u óox (Bromisum alicastrum), son comida para venados, pecaríes y pavos de monte, que permanecerían encerrados dentro del muro de piedras que resguardaba esta vegetación manejada (Gómez-Pompa, Flores y Sosa, 1987: 14). A su vez, Hamblin (1984) describe para la isla de Cozumel, Quintana Roo, una práctica semejante con corrales hechos de piedra para confinar pecaríes, construidos en "bosques” de palmas que servían de alimento.
} 
aquí, "milpa convencional" (mc). Más bien, ésta nos servirá de base comparativa para hacer un primer acercamiento descriptivo e interpretativo a la que hemos denominado "milpa comedero-trampa" (mc-t). En este caso, la agricultura y la cacería constituyen un nexo tecnológico para obtener presas en espacios muy concretos y altamente especializados dentro del territorio. Se definen los componentes técnicos y la organización social involucrada que caracterizan a esta milpa comederotrampa, enriqueciendo así lo que hasta la fecha se conoce como sistema de milpa bajo RTQ, a la vez que se plantea un nuevo enfoque del modelo de garden hunting.

\section{Métodos}

Área de estudio

En la Península de Yucatán, se estudiaron ocho comunidades mayas, de las cuales siete - Chankaj Veracruz, X-Hazil Sur, Uh May, X-Pichil, Señor, San Antonio Nuevo y Kopchén - se localizan en el centro de Quintana Roo y son habitadas por mayas históricamente autodenominados "macehuales", esto es, descendientes de los mayas rebeldes del conflicto armado del siglo xix conocido como "Guerra de Castas" (Reed, 1987), que buscaron refugio en la selva del actual estado de Quintana Roo. A su vez, la otra comunidad maya (20 de Noviembre), no macehual, se localiza en la región de Calakmul, Campeche. Asimismo, valiéndonos del concepto de región maya (Coe, 1986), a modo comparativo, se incluyó en el presente estudio una novena comunidad (Nuevo Becal) localizada también en Calakmul, pero conformada por gente mestiza (figura 1).

Las principales actividades productivas y económicas de estas comunidades son la agricultura para autoconsumo con base en maíz (Zea mays), frijol (Phaseolus spp.) y calabaza (Cucurbita spp.), la extracción forestal comercial de maderas "preciosas" como la caoba (Swietenia macrophilla) y el cedro (Cedrela odorata) (concretamente en Chankaj Veracruz, X-Hazil Sur, Uh May, 20 de Noviembre y Nuevo Becal), algunos negocios familiares (abarrotes, papelería, refaccionaria, carpintería) y servicio de transporte privado, el cultivo comercial de chile habanero y jalapeño (Capsicum spp.) y de hortalizas en invernaderos, la apicultura, la venta de carbón vegetal, y la extracción de chicle (Manilkara zapota), de semillas de caoba y de hojas de la palma xate (Chamaedora spp.) (principalmente en Nuevo Becal). Además, muchos habitantes buscan trabajos asalariados (jornales) en la ciudad de Felipe Carrillo Puerto o en la zona hotelera del polo turístico de la Rivera Maya, Quintana Roo; y en el caso de 20 Noviembre y Nuevo Becal, algunos pobladores migran a los EUA. En las nueve comunidades también pescan y cazan para complementar su alimentación y realizar venta parcial (Arce-lbarra, 2007; Argüelles et al., 2009; CONAFOR, 2009; Bello y Estrada, 2011).

Una característica relevante del área geográfica que conforma la Península de Yucatán es que presenta una plataforma caliza que redunda en un paisaje microondulado de no más de $15 \mathrm{~m}$ de altura, con suelos someros en superficies pequeñas 


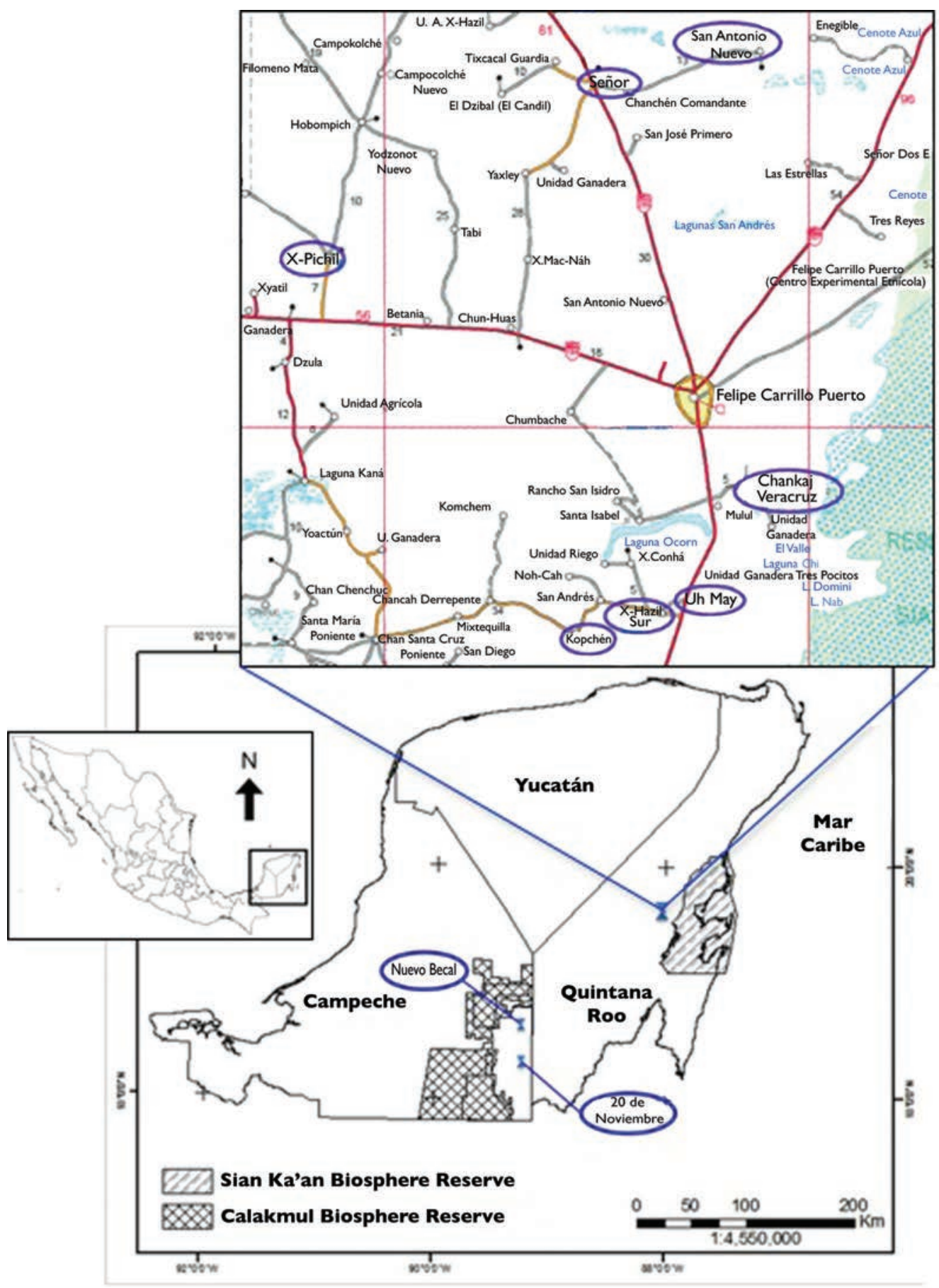

Figura 1. Comunidades rurales en la Península de Yucatán donde se realizó el trabajo de campo del presente estudio (febrero-abril de 2011).

Diseño cartográfico realizado por David Uribe Villavicencio.

Autoría del fragmento de mapa: Secretaría de Comunicaciones y Transportes (2006). 
de entre 400 y $4000 \mathrm{~m}^{2}$, y de mucha pedregosidad, no aptos para mecanización ni modificaciones topográficas (Bello y Estrada, 2011). Además del suelo, otra gran limitante ambiental para la agricultura en la Península, a menos que sea por sistema/ técnica de RTQ, es la ausencia de corrientes de agua superficiales, por la permeabilidad del terreno que filtra el agua de lluvia (que además es errática y cambiante de un año a otro); pero se compensa al formarse cauces subterráneos que llegan a aflorar en un sistema de estructuras como cenotes, grutas, aguadas y lagunas (Terán y Rasmussen, 1994; Bello y Estrada, 2011). En la región, la mayoría de las comunidades, incluidas las nueve visitadas para este estudio, contienen en sus territorios o están rodeadas de extensas áreas de bosques tropicales húmedos y subhúmedos, entremezcladas con vegetación secundaria, áreas de cultivo, cuerpos de agua y algunos pastizales inducidos para la producción ganadera (INE, 1996 y 2000; Escamilla et al., 2000; Argüelles et al., 2009; CONAFOR, 2009; Bello y Estrada, 2011).

\section{Trabajo de campo y análisis de la información}

El presente estudio es parte de una investigación de mayor amplitud, donde el objetivo general fue identificar de un modo holístico los usos y costumbres que rigen y regulan el aprovechamiento y manejo que los mayas hacen de la fauna silvestre por medio de la actividad de la cacería, en su contexto ambiental y como una expresión material, sociocultural y simbólica de su cosmovisión. Usos y costumbres que, a su vez, permiten distinguir aquellas normas consuetudinarias mayas en torno a esta actividad de subsistencia (Santos-Fita, 2013).

En el transcurso de la fase de campo, al convivir y participar cada vez más del quehacer de los cazadores mayas en sus comunidades, fueron revelados in situ aspectos relacionados con la cacería, pero que no estaban contemplados al momento de formular la propuesta inicial de investigación ni informados en la literatura revisada; entre ellos, una práctica de manejo del hábitat orientada a atraer determinada fauna silvestre para ser cazada, y en donde están presentes elementos del sistema agrícola de la milpa bajo RTQ. Para una mejor interpretación, se hizo a posteriori una revisión bibliográfica de autores que desde la década de 1930 han descrito y caracterizado los componentes distintivos de la milpa maya o kool (Pérez-Toro, 1945; Hernández X., 1981; Zizumbo et al., 1992; Terán y Rasmussen, 1994; Hernández X., Bello y Levy, 1995) y de diversos sistemas agrícolas en otras regiones de México donde también se realiza una agricultura de RTQ (Rojas-Rabiela, 1991; Casas et al., 1994), incluyendo aspectos sobre cacería (Terán y Rasmussen, 1994). Dichos componentes fueron agrupados de la siguiente manera: a) finalidad, nombre local (en maya yucateco) y tamaño; $b$ ) aspectos técnicos relacionados con el proceso de la RTQ, especies cultivadas priorizadas, e instituciones locales y prácticas rituales asociadas al ciclo agrícola; $c$ ) relación con la actividad de la cacería, y d) formas de organización social, ubicación dentro del territorio y situación actual en la que se encuentra el sistema milpero.

La información derivada del método etnográfico —observación participante, entrevistas y "excursiones-guiadas" - (Sandoval, 1996), especialmente la propor- 
cionada por los cazadores, delimitó y caracterizó a la milpa comedero-trampa; esta evidencia se cotejó con la información bibliográfica sobre la agricultura de RTQ y la milpa maya convencional para identificar similitudes y diferencias. Entre febrero y abril de 2011 se entrevistaron 33 personas de las siete comunidades mayas de la zona centro de Quintana Roo. Asimismo, se entrevistó a 13 moradores de 20 de Noviembre y Nuevo Becal, en la región de Calakmul, Campeche (cuadro 1). Fueron hombres milperos, entre 27 y 65 años de edad, que ejercen o ejercieron la actividad de caza con mayor o menor grado de dedicación. Paralelamente, se visitaron 3 milpas comedero-trampa (dos en fase de construcción y una en funcionamiento), y se compararon con las respectivas milpas convencionales de esos mismos cazadores. A partir de las coordenadas tomadas en GPS, se ubicaron localizaciones y distancias sobre imágenes satelitales (Google Earth, versión 6.1.0.5001).

El software QSR N6® (QSR International, Pty Ltd 2002) nos permitió capturar, organizar y sistematizar toda la información (cualitativa) para facilitar su posterior análisis. Los registros de audio tomados con grabadora digital, con la infor-

\begin{tabular}{|c|c|c|c|}
\hline Comunidad & $\begin{array}{l}\text { Grupo } \\
\text { étnico }\end{array}$ & $\begin{array}{c}\text { Número } \\
\text { de entrevistados }\end{array}$ & Situación actual \\
\hline $\begin{array}{c}\text { Chankaj Veracruz } \\
\text { (Quintana Roo) }\end{array}$ & maya & 10 & $\begin{array}{c}\text { dos cazadores tienen cada uno } \\
\text { una milpa comedero-trampa } \\
\text { en construcción }\end{array}$ \\
\hline $\begin{array}{c}\text { X-Hazil Sur } \\
\text { (Quintana Roo) }\end{array}$ & maya & 10 & $\begin{array}{l}\text { dos cazadores tienen cada uno } \\
\text { una milpa comedero-trampa } \\
\text { en construcción }\end{array}$ \\
\hline $\begin{array}{c}\text { Uh May } \\
\text { (Quintana Roo) }\end{array}$ & maya & 6 & $\begin{array}{l}\text { un cazador tiene una } \\
\text { milpa comedero-trampa } \\
\text { en funcionamiento (se visitó) }\end{array}$ \\
\hline $\begin{array}{c}\text { Señor } \\
\text { (Quintana Roo) }\end{array}$ & maya & 3 & $\begin{array}{l}\text { un cazador tiene dos milpas } \\
\text { comedero-trampa } \\
\text { en construcción (se visitaron) }\end{array}$ \\
\hline $\begin{array}{c}\text { X-Pichil } \\
\text { (Quintana Roo) }\end{array}$ & maya & 2 & \\
\hline $\begin{array}{c}\text { Kopchén } \\
\text { (Quintana Roo) }\end{array}$ & maya & 1 & $\begin{array}{l}\text { un cazador tiene una milpa comede- } \\
\text { ro-trampa } \\
\text { en funcionamiento }\end{array}$ \\
\hline $\begin{array}{l}\text { San Antonio Nuevo } \\
\text { (Quintana Roo) }\end{array}$ & maya & 1 & \\
\hline $\begin{array}{l}20 \text { de Noviembre } \\
\text { (Campeche) }\end{array}$ & maya & 9 & \\
\hline $\begin{array}{l}\text { Nuevo Becal } \\
\text { (Campeche) }\end{array}$ & mestizo & 4 & \\
\hline
\end{tabular}

CuAdro 1. Número de entrevistados por comunidad (todas localizadas en la Península de Yucatán) (febrero-abril de 2011) referente al estudio sobre las milpas comedero-trampa. 
mación obtenida en trabajo de campo, se encuentran disponibles para consulta en El Colegio de la Frontera Sur-Unidad San Cristóbal (solicitar con el primer autor del presente estudio).

\section{Resultados y discusión}

Al realizar una búsqueda bibliográfica (en estudios sobre cacería y sistemas agrícolas) de posibles registros previos y por comunicación personal con varios investigadores sobre la existencia, descripción e interpretación de estas milpas comedero-trampa no se encontró información. Respecto a Mesoamérica, tampoco contamos con referencias en los documentos prehispánicos y del período colonial (Mario Humberto Ruz, comunicación personal, 2011), aunque eso no signifique que las milpas comedero-trampa no se usaran ya como una de las estrategias de cacería entre mayas y, tal vez, entre otros grupos indígenas.

En el cuadro 2, se presentan los componentes distintivos que fueron identificados en la literatura especializada sobre milpa y RTQ. A su vez, se describe y delimita a la milpa comedero-trampa a partir de sus semejanzas y, sobre todo, diferencias (conceptuales y técnicas) respecto a la milpa convencional.

Finalidad, nombre local y tamaño

La principal diferencia, conceptual, entre una milpa convencional y una milpa comedero-trampa consiste en que en esta última la siembra de cultivos agrícolas interesa exclusivamente para atraer y cazar determinadas especies de vertebrados terrestres; todos los cazadores la conceptualizan como si fuera un tipo de "trampa". Entonces, a nuestro juicio, la milpa comedero-trampa queda fuera del contexto de "milpa para autoconsumo", esto es, la considerada aquí como convencional y ampliamente descrita y reconocida por investigadores y público en general, al no ser sus cultivos cosechados y aprovechados por el milpero y familiares, sino destinados para la fauna silvestre.

A pesar de ciertas divergencias entre lo que mencionaron los cazadores, en general todos ellos coinciden en la parte descriptiva del área de milpa comederotrampa, aunque le asignen distintos nombres para definirla. Siempre la conciben como si fuera una milpa, además de usar el término kool. De ahí que propongamos el nombre de "milpa comedero-trampa", a sabiendas de que en maya yucateco el término $\mathrm{kool}$, además de "milpa”, también se refiere al sistema de RTQ como un todo, o incluso sólo a la fase de tumba (Gómez, 2009: 141). Las siguientes afirmaciones ilustran el consenso que hay entre los entrevistados sobre la intencionalidad de las milpas comedero-trampa:

- Haces una milpita no muy grande especialmente para sembrar, sólo para tirar venado, jabalí [pecarí]. [...] Ahora no muchos lo hacen, sólo los que andamos más de cacería (Julio Poot, 29 años; comunidad de X-Hazil Sur, Quintana Roo). 


\begin{tabular}{|c|c|c|c|}
\hline \multicolumn{2}{|c|}{ Componente $^{\mathrm{a}}$} & Milpa convencional ${ }^{\mathrm{a}, \mathrm{b}}$ & Milpa comedero-trampa ${ }^{b}$ \\
\hline \multicolumn{2}{|c|}{ Finalidad (principal) } & Obtener cosechas para autoconsumo. & $\begin{array}{l}\text { Atraer fauna silvestre y así poder } \\
\text { cazarla. }\end{array}$ \\
\hline \multicolumn{2}{|c|}{$\begin{array}{c}\text { Nombre local (en maya } \\
\text { yucateco) }\end{array}$} & ix kool; kool & $\begin{array}{l}\text { - Chan kool; pet kool; mejen kool; met } \\
\text { pach. } \\
\text { - Ch'een ti' u ts'oon; k'uuchil ts'oon; } \\
\text { yaanten junp'éel. }\end{array}$ \\
\hline \multicolumn{2}{|c|}{ Tamaño } & Entre $1-3$ ha $\left(10000-30000 \mathrm{~m}^{2}\right)$. & Entre 1-3 mecates $\left(400-1200 \mathrm{~m}^{2}\right)$ \\
\hline \multicolumn{2}{|c|}{$\begin{array}{l}\text { Tipo de monte selec- } \\
\text { cionado (en caso de } \\
\text { ser milpa de } 1^{\text {er }} \text { año) }\end{array}$} & $\begin{array}{l}\text { - Selva secundaria (mejor en fases } \\
\text { avanzadas de la sucesión). } \\
\text { - Cada vez menos en selva primaria. }\end{array}$ & $\begin{array}{l}\text { - Selva secundaria (de 8-10 o más } \\
\text { años de barbecho). } \\
\text { - Quemadales de 2-3 años (dentro de } \\
\text { monte alto). }\end{array}$ \\
\hline \multicolumn{2}{|c|}{ Brecheo (joolch'ak) } & $\begin{array}{l}\text { Completo; alrededor del terreno selec- } \\
\text { cionado, para señalarlo y como base } \\
\text { para la medición. }\end{array}$ & $\begin{array}{l}\text { Sólo una brecha pequeña de acceso al } \\
\text { lugar elegido. }\end{array}$ \\
\hline \multicolumn{2}{|c|}{ Medición (p’isk’aax) } & $\begin{array}{l}\text { Completa; usando la medida de } 1 \\
\text { mecate }\left(20 \times 20 \mathrm{~m}=400 \mathrm{~m}^{2}\right)\end{array}$ & Se usa la medida del mecate. \\
\hline \multirow[b]{3}{*}{ 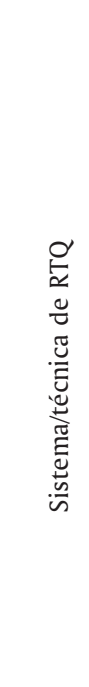 } & $\begin{array}{c}\text { Roza } \\
\text { (ch'akbe'en) }\end{array}$ & $\begin{array}{c}\text { Completa; de herbáceas, bejucos y } \\
\text { arbustos. }\end{array}$ & $\begin{array}{l}\text { Selectiva y localizada; se hace justo } \\
\text { donde irán los cultivos. }\end{array}$ \\
\hline & $\begin{array}{l}\text { Tumba (kool; } \\
\text { ch'akche') }\end{array}$ & $\begin{array}{l}\text { - Selectiva (se dejan en pie los árboles } \\
\text { útiles); de árboles de diferente tama- } \\
\text { ño. Se mantienen sus tocones. } \\
\text { - La época de tumba dependerá del } \\
\text { tipo de monte. }\end{array}$ & $\begin{array}{c}\text { Poco exhaustiva, dejando varios } \\
\text { árboles en pie de diferentes grosores, } \\
\text { aunque no útiles. }\end{array}$ \\
\hline & $\begin{array}{l}\text { Quema } \\
\text { (tóok) }\end{array}$ & $\begin{array}{l}\text { - Completa; de toda la vegetación } \\
\text { previamente derribada. } \\
\text { - Se hace justo antes (entre mayo y } \\
\text { junio) del inicio de la época de lluvias. } \\
\text { - El milpero recibe el apoyo de familia- } \\
\text { res y otros ayudantes. } \\
\text { - Se hace una guardarraya o brecha } \\
\text { cortafuego para evitar que el fuego se } \\
\text { expanda hacia la vegetación circun- } \\
\text { dante convirtiéndose en incendio } \\
\text { forestal. }\end{array}$ & $\begin{array}{l}\text { - Por lo general no se usa la quema } \\
\text { como tal, pero se puede dar de ma- } \\
\text { nera microlocalizada. } \\
\text { - No hay guardarraya. } \\
\text { - Los árboles tumbados se acumulan } \\
\text { al no quemarse. }\end{array}$ \\
\hline
\end{tabular}

CuAdro 2. Descripción y delimitación de la milpa comedero-trampa a partir de la comparativa con las características de una milpa convencional, en el contexto rural de la Península de Yucatán.

a Con base en Pérez-Toro, 1945; Hernández X., 1981; Zizumbo et al., 1992; Terán y Rasmussen, 1994; Hernández X., Bello y Levy, 1995.

${ }^{b}$ Con base en las entrevistas y observaciones directas en trabajo de campo (2011). 


\begin{tabular}{|c|c|c|c|}
\hline \multirow{3}{*}{ 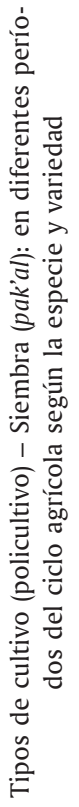 } & $\begin{array}{l}\text { Cultivos } \\
\text { principales }\end{array}$ & $\begin{array}{l}\text { - Maíz (Zea mays) } \\
\text { - Frijol (Phaseolus spp.; P. vulgaris) } \\
\text { - Calabaza (Cucurbita spp.) }\end{array}$ & $\begin{array}{c}\text { - Camote } \\
\text { - Jícama } \\
\text { - Calabaza } \\
\text { (Obs.: todos en menor cantidad que } \\
\text { en la milpa convencional) }\end{array}$ \\
\hline & $\begin{array}{c}\text { Otros } \\
\text { cultivos } \\
\text { (algunos }^{\text {ejemplos) }}\end{array}$ & $\begin{array}{c}\text { - Calabazo (Lagenaria siceraria) } \\
\text { - Jícama (Pachyrrhizus erosus) } \\
\text { - Camote (Ipomoea batatas) } \\
\text { - Ibes (frijol blanco; P. lunatus) } \\
\text { - Makal o ñame (Xanthosoma yucata- } \\
\text { nense) }\end{array}$ & $\begin{array}{c}\text { - Frijol } \\
\text { - Ibes } \\
\text { - Maíz (Obs.: muy poco usado) }\end{array}$ \\
\hline & $\begin{array}{l}\text { Pet pach } \\
\text { o pach } \\
\text { pak'al }^{\mathbf{d}}\end{array}$ & $\begin{array}{l}\text { - Tomate (Solanum lycopersicum) } \\
\text { - Chile (Capsicum spp.) } \\
\text { - Sandía (Citrullus lanatus) } \\
\text { - Calabaza (Cucurbita pepo) } \\
\text { - Jícama, makal, camote, entre otros. }\end{array}$ & $\begin{array}{c}\text { - La milpa comedero-trampa es } \\
\text { nombrada como pet pach por algunos } \\
\text { cazadores, por similitud de tamaño. } \\
\text { - No hay siembra de cultivos hortí- } \\
\text { colas. }\end{array}$ \\
\hline \multicolumn{2}{|c|}{$\begin{array}{l}\text { Deshierbe } \\
\text { (páak kool) }\end{array}$} & $\begin{array}{l}\text { Completo; eliminar la vegetación } \\
\text { arvense que compite con el maíz du- } \\
\text { rante su fase de desarrollo vegetativo. }\end{array}$ & $\begin{array}{c}\text { - No hay deshierbe porque muchas } \\
\text { de las plantas -rebrotes y herbáceas- } \\
\text { son también alimento para (atraer) } \\
\text { la fauna. } \\
\text { - Únicamente se da donde están } \\
\text { presentes los cultivos (destinados a } \\
\text { atraer las presas). }\end{array}$ \\
\hline \multicolumn{2}{|c|}{ Cosecha (jooch) } & $\begin{array}{l}\text { - Completa; tiempo de cosecha muy } \\
\text { amplio y variable al involucrar espe- } \\
\text { cies y variedades de diferentes ciclos } \\
\text { de maduración. También en función de } \\
\text { si se cosechan los frutos tiernos o los } \\
\text { secos, como ocurre con el maíz. } \\
\text { - Hay casos en que los milperos dejan } \\
\text { intencionadamente parte del cultivo } \\
\text { sin cosechar (en los márgenes de la } \\
\text { milpa) para que ciertas especies de } \\
\text { fauna silvestre se acostumbren a llegar } \\
\text { y se facilite el cazarlas. }\end{array}$ & $\begin{array}{l}\text { - No hay cosecha. } \\
\text { - Todo el cultivo se deja para la fauna } \\
\text { silvestre, a modo de "comedero", } \\
\text { pero a la vez de "trampa", para que } \\
\text { se acostumbren a llegar ciertos tipos } \\
\text { de animales y así poder cazarlos } \\
\text { (interesan las mismas especies que en } \\
\text { la milpa convencional). }\end{array}$ \\
\hline
\end{tabular}

' No se incluyen aquí los árboles frutales ni otras especies consideradas útiles.

${ }^{d}$ Es habitual reservar una parte (de 1-3 mecates: 400-1 $200 \mathrm{~m}^{2}$ ) del área de milpa, con un suelo más favorable al tener pocas piedras y cierta profundidad (hasta $20-50 \mathrm{~cm}$ ), y con agua siempre disponible, para la siembra de determinados cultivos, entre ellos los hortícolas (Estrada, Bello y Velazco, 2011: 112). 


\begin{tabular}{|c|c|c|}
\hline $\begin{array}{c}\text { Prácticas rituales ma- } \\
\text { yas asociadas al ciclo } \\
\text { agrícola }\end{array}$ & $\begin{array}{l}\text { - Antes de la tumba (en caso de ser } \\
\text { monte alto: más de } 20 \text { años). } \\
\text { - Antes de la quema. } \\
\text { - Para petición de lluvias: ceremonia } \\
\text { del Ch'áa Cháak. } \\
\text { - De agradecimiento por la cosecha: } \\
\text { ceremonia del Janli Kool. }\end{array}$ & $\begin{array}{l}\text { No involucra ningún tipo } \\
\text { de ceremonia. }\end{array}$ \\
\hline $\begin{array}{l}\text { Relación con la prácti- } \\
\text { ca de la cacería }\end{array}$ & $\begin{array}{l}\text { - Cazar en la ix kool le sirve al milpero } \\
\text { como fuente de alimento y otros } \\
\text { productos y, a la vez, como control } \\
\text { al daño y depredación excesiva de } \\
\text { cultivos. } \\
\text { - Cacería selectiva u oportunista. } \\
\text { - Técnicas más frecuentes: espiar, bús- } \\
\text { queda; también uso de trampas. } \\
\text { - Aplica el actual modelo de "cacería } \\
\text { en áreas cultivadas o huertos" (garden } \\
\text { hunting model), en sus diferentes } \\
\text { interpretaciones. } \\
\text { - Implica reglas y normas sociales } \\
\text { comunitarias de "buen cazador". }\end{array}$ & $\begin{array}{l}\text { - Se conceptualiza como "trampa". } \\
\text { - Visiblemente intencional y direccio- } \\
\text { nada (selectiva) a ciertas especies. } \\
\text { - Técnica: espiar. } \\
\text { - No se ajusta al actual modelo de } \\
\text { garden hunting, tal y como se propuso } \\
\text { y fue reinterpretado. }\end{array}$ \\
\hline $\begin{array}{c}\text { Forma de organización } \\
\text { social }\end{array}$ & $\begin{array}{c}\text { El milpero se puede apoyar en } \\
\text { familiares, parientes lejanos, amigos } \\
\text { y conocidos para realizar las distintas } \\
\text { labores durante todo el ciclo agrícola } \\
\text { (incluyendo cazar). }\end{array}$ & De carácter enteramente individual. \\
\hline $\begin{array}{l}\text { Ubicación dentro } \\
\text { del territorio }\end{array}$ & $\begin{array}{l}\text { - Conocida por toda la comunidad. } \\
\text { - Relativamente cerca del poblado o } \\
\text { de otras ix kool. } \\
\text { - En determinadas comunidades mayas } \\
\text { se establecen por rumbos familiares. } \\
\text { - Existen caminos de acceso definidos } \\
\text { y visibles; incluso se hacen al lado de } \\
\text { carreteras. } \\
\text { - Debido a la incertidumbre pluvial, } \\
\text { cada milpero realiza simultáneamente } \\
\text { dos o tres ix kool, que se atienden en } \\
\text { espacios separados (incluyendo los so- } \\
\text { lares o huertos familiares). Esto hace } \\
\text { aumentar las posibilidades de obtener } \\
\text { cosecha. }\end{array}$ & $\begin{array}{l}\text { - Sólo el cazador propietario sabe } \\
\text { dónde se localiza(n). } \\
\text { - Situada lejos del poblado y de las } \\
\text { zonas donde se trabajan las ix kool. } \\
\text { - Sin caminos o rutas de acceso } \\
\text { definidas y visibles. }\end{array}$ \\
\hline $\begin{array}{c}\text { Estado o situación } \\
\text { actual }\end{array}$ & $\begin{array}{l}\text { A pesar de las circunstancias produc- } \\
\text { tivas y socioeconómicas desfavorables } \\
\text { del momento actual, sigue siendo el } \\
\text { principal modo de subsistencia de } \\
\text { las comunidades rurales en todo el } \\
\text { sureste de México. }\end{array}$ & Práctica poco común. \\
\hline
\end{tabular}

e Terán y Rasmussen, 1994: 185-187; Estrada, Bello y Velazco, 2011: 113-114.

${ }^{f}$ Linares, 1976; Neusius, 1996: 276; VanDerwarker, 2006: 148-151. 
—Lo que siembras allá no es para comer, es especial para tirar venado. [...] Ko'ox meetik jump'iit chan kool, chéen ti'al in ts'oonik kéej ("vamos hacer un poco de milpita sólo para matar venado") (don Aurelio Cauich, de 48 años, comunidad de Chankaj Veracruz, Quitana Roo).

-Donde ves que andan los animales, haces un poco de tumba y siembras camote, calabaza, jícama, maíz. [...] Para que lleguen los animales. Es especial para que lleguen, para que tires (don Facundo Puc, de 55 años, comunidad de Uh May, Quintana Roo).

—Son milpas para espiar. Antes se hacían más. [...] No son milpas para consumo nuestro. Son como trampas (don "Chak Pool”, de 46 años, comunidad de Señor, Quintana Roo).

En maya yucateco a esta práctica/“trampa” de cacería la llaman por diversos nombres o expresiones. Los mencionados fueron: a) chan kool, pet kool y mejen $\mathrm{kool}$, atendiendo al tamaño, siendo una "milpa pequeña" diferente a la ix kool; b) pet pach, por cierta similitud con el espacio pequeño dedicado a cultivar hortalizas de temporal, dentro de la ix kool; c) ch'een ti' u ts'oon ("sólo para que tire/cace”); d) kúuchil ts'oon ("lugar de la tiradera/cacería”), y e) yaanten junp’éel maanchaj te'elo' ("tengo una mancha”, "es como una mancha, un poco de milpa especialmente para tirar”, Julio Poot, de 29 años, comunidad de X-Hazil Sur, Quintana Roo). Atendiendo a estos nombres y expresiones, la milpa comederotrampa es denominada localmente así por su función, pero sobre todo por el tamaño, y parte de la referencia de la ix kool (la milpa convencional). El tamaño es muy reducido en comparación con una milpa convencional, tan sólo 1-3 mecates (400-1 $\left.200 \mathrm{~m}^{2}\right)$ (figuras 2a y 2b).

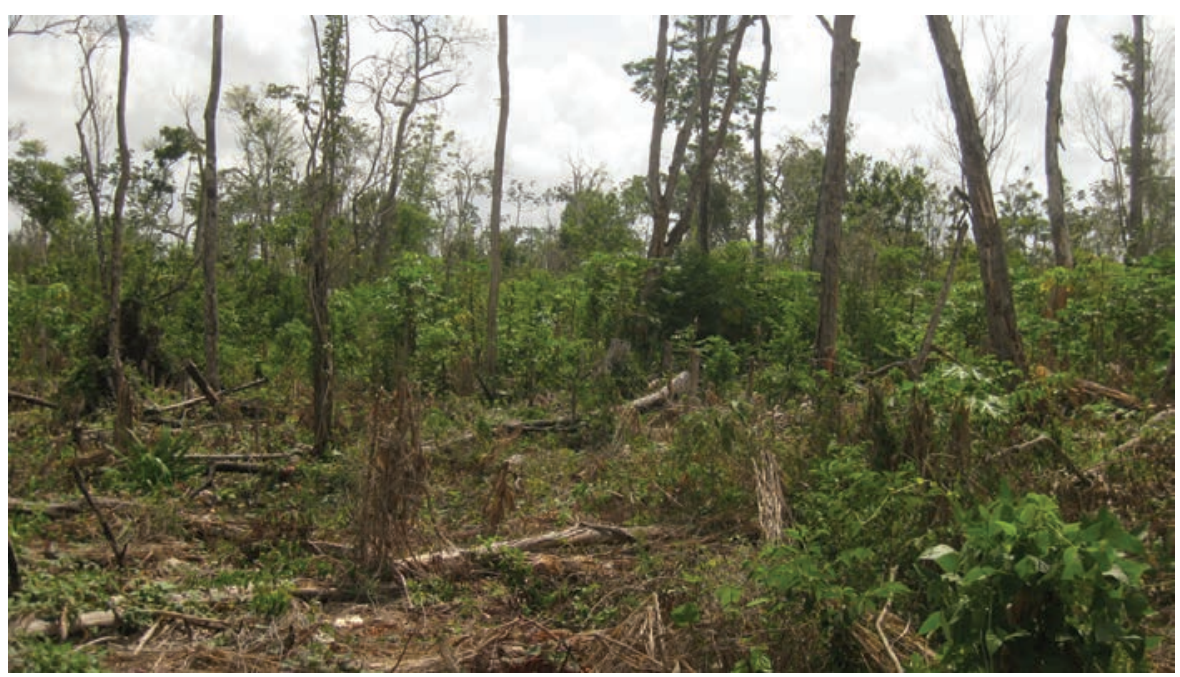

FIGURA 2a. Milpa convencional (ix kool, tamaño: 2 ha $=20000 \mathrm{~m}^{2}$ ), propiedad de don Facundo Puc, de 55 años, comunidad de Uh May, Quintana Roo. Fuente: fotografía realizada por Dídac Santos-Fita (2001). 


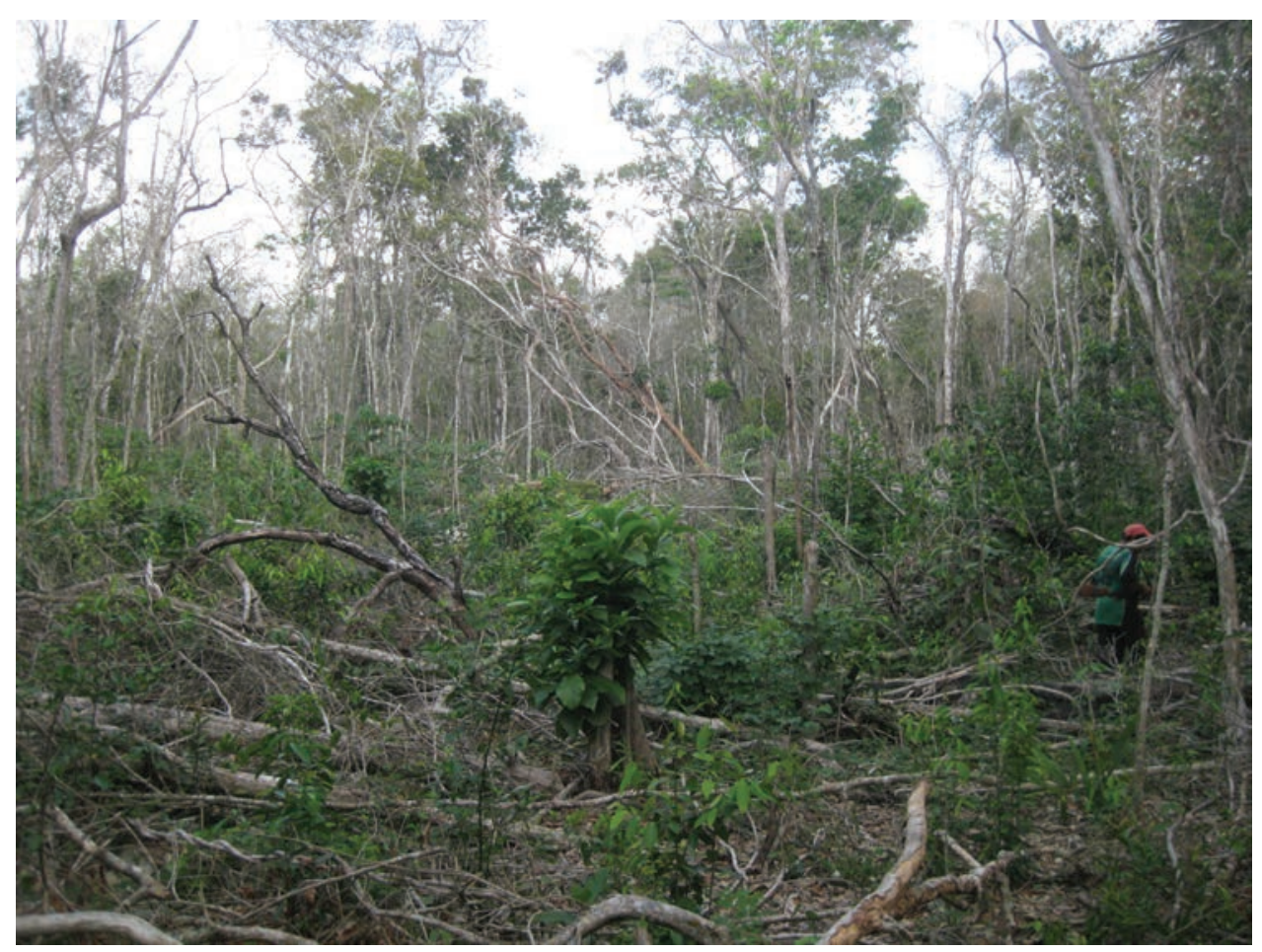

FIGURA 2b. Milpa comedero-trampa (tamaño: 3 mecates [1 $\left.200 \mathrm{~m}^{2}\right]$ ), propiedad de don Facundo Puc, de 55 años, comunidad de Uh May, Quintana Roo. Fuente: fotografía realizada por Dídac Santos-Fita (2011).

Aspectos técnicos relacionados con la RTQ, especies cultivadas priorizadas, e instituciones locales y prácticas rituales asociadas al ciclo agrícola

El cazador desbroza un área dentro de vegetación secundaria de aproximadamente 8 o más años de barbecho (huamil, acahual). Otra opción es aprovechar quemadales de 2-3 años de antiguiedad, muchas veces dentro de monte alto (vegetación primaria). A diferencia de en una milpa convencional, posterior a la roza y tumba no se acostumbra aplicar la quema, únicamente a veces de manera microlocalizada. Las tres ocasiones que se visitaron milpas comedero-trampa — dos en fase de construcción y una en funcionamiento- se observó que el proceso de RTQ no llegaba a ser del todo completo como a la hora de hacer una milpa convencional. Además de dejar en pie varios árboles, esto es, que la tumba no es tan exhaustiva, las áreas no se habían quemado por completo. No se observó guardarraya, la cantidad de troncos caídos acumulados era notable en algunos rincones y, lo más destacable, había quema pero microlocalizada (figura 3). 




FIGURA 3. Quema microlocalizada (círculos en color azul) en la milpa comedero-trampa de don Facundo Puc, de 55 años, Comunidad de Uh May, Quintana Roo.

Fuente: fotografía realizada por Dídac Santos-Fita. (2011).

Para atraer y acostumbrar a los animales, en la milpa comedero-trampa el cazador prioriza cultivar el camote (Ipomoea batatas), además de jícama (Pachyrrhizus erosus), calabaza (Cucurbita spp.) y a veces frijol (Phaseolus spp.) e ibes ( $P$. lunulatus) (figura 4). Los entrevistados mencionaron que también llegan a cultivar el maíz (Zea mays), pero a diferencia de la milpa convencional aquí no es el cultivo primordial, por las dificultades y tardanza en crecer en espacios pequeños tan sombreados, debido a la altura de la vegetación circundante. Incluso algunos únicamente le dan cierta importancia porque facilita que "suba la jícama". Entonces, la mayoría de las milpas comedero-trampa terminan siendo camotales, que también dificultan el crecimiento del maíz (ver sobre el efecto camote-maíz en Valverde, 1976: 47-48). Otra ventaja del camote es que no se ve afectado (al crecer éste bajo tierra) en caso de que el cazador decida quemar partes del área para acostumbrar al venado cola blanca a que entre a comer los nuevos retoños. Asimismo, estará disponible en época de sequía (abril-mayo) para su consumo justo en el momento en que los animales se concentran principalmente en zonas boscosas de vegetación primaria y secundaria en busca de alimentos. En la milpa convencional, regida con base al ciclo del maíz, frijol y calabaza, desde septiembre — cuando surgen los primeros elotes tiernos- hasta completar la 
cosecha a finales de noviembre, los animales típicamente frecuentan el lugar para alimentarse, aumentando así las posibilidades de caza. Sin embargo, el venado cola blanca entra en la milpa convencional justo después de la quema con las primeras lluvias (julio-agosto) para comer retoños (Mandujano y Rico-Gray, 1991: 179-180; observación personal en trabajo de campo, 2011).

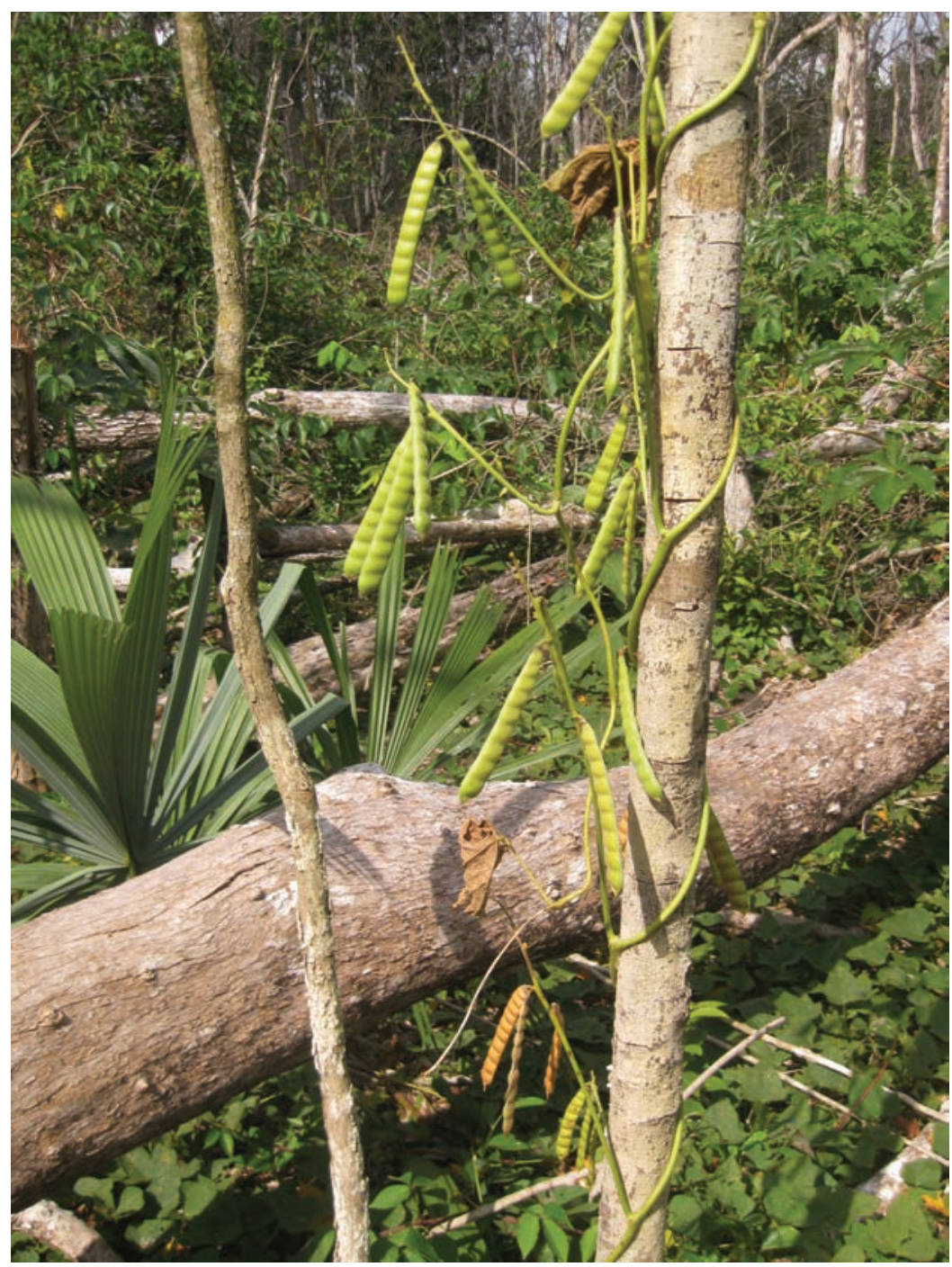

Figura 4. Semillas de jícama (Pachyrrhizus erosus) y, al fondo en el suelo, hojas de camote (Ipomoea batatas) en la milpa comedero-trampa de don Facundo Puc, de 55 años, comunidad de Uh May, Quintana Roo. Fuente: fotografía realizada por Dídac Santos Fita (2011). 
Asimismo, según los entrevistados, para los mayas el realizar prácticas ceremoniales a lo largo del ciclo agrícola y del sistema de RTQ depende, en parte, del tamaño de la milpa. Si es monte alto, antes de abrir (empezar a delimitar por mecates) ${ }^{3}$ una nueva milpa convencional, de mínimo una hectárea de dimensión, los milperos mayas (sobre todo en los del centro de Quintana Roo y oriente de Yucatán) solicitan el permiso de las potencias sobrenaturales, ofreciéndoles la bebida ritual sakjab $b^{4}$ mediante rezos. Lo mismo ocurre para las fases de tumba, quema, siembra y petición de lluvias — ceremonia del Ch'áa Cháak-, y después de la cosecha —ceremonia del Janli Kool. Además del sajkab se ofrenda baalche', ${ }^{5}$ tortillas y "panes sagrados" de maíz, y carne de animales domesticados y de monte (Love y Peráza, 1984: 262; Villa Rojas, 1987: 307-335; Bartolomé, 1988: 230-246; Terán y Rasmussen, 1994: 191-192, 199, 229-230 y 243; observación personal en trabajo de campo). ${ }^{6}$ Al contrario, cuando se trata de una milpa comedero-trampa, al ser de tamaño muy reducido (no acostumbran a pasar de 3 mecates, es decir, de $1200 \mathrm{~m}^{2}$ ), no es necesario solicitar permiso alguno a dioses, espíritus y otras clases de fuerzas sobrenaturales para hacerla. En este sentido, pareciera que las instituciones locales son flexibles y toleran ciertas particularidades en el uso y manejo que los pobladores hacen de los espacios y recursos naturales, en este caso, sin la necesidad de una práctica ritual referente a las milpas comedero-trampa.

En conclusión, la milpa comedero-trampa se presenta como una variante de milpa, donde hay aspectos técnicos del proceso de la RTQ y de las especies cultivadas que se manejan distinto (e.g., la quema) o simplemente no se priorizan (e.g., el propio maíz y las prácticas ceremoniales). Además, al no haber un único término o expresión local en maya yucateco exacto para nombrarla, tampoco impide que los agricultores la conciban como si fuera una milpa; no es casualidad que justamente mencionen el vocablo kool como parte del nombre.

\section{Relación con la actividad de la cacería}

Diversas especies de animales aprovechan temporalmente los espacios agrícolas para obtener alimentos, lo que les permite soportar períodos de escasez estacional en otros parches de vegetación (Smith, 2005). En la lógica del milpero maya, la cacería dentro de su milpa convencional le proporciona alimento y otros productos, a la vez que le permite controlar el daño o depredación excesiva ocasionados por

\footnotetext{
${ }^{3}$ Medida de distancia utilizada por los mayas, de $20 \times 20 \mathrm{~m}: 1$ mecate $=400 \mathrm{~m}^{2}$.

${ }^{4}$ Bebida ceremonial, sagrada para los mayas, hecha de agua con masa de maíz sin añadirle cal, a diferencia de cuando se trata de elaborar tortillas (Barrera-Vásquez et al., 1980).

${ }^{5}$ Bebida ceremonial entre los indígenas mayas y lacandones (Barrera-Vásquez et al., 1980; Bartolomé, 1988: 230; Marion, 1994; Gabriel, 2007: 156-171), la cual aún es posible observar en las ceremonias de algunas comunidades (Love y Peráza, 1984; Gabriel, 2007). Se hace de la fermentación en alcohol de la corteza del árbol Baalche' (Lonchocarpus violaceus; Fabaceae) mezclada con miel de abejas nativas meliponas y trigonas (e'joox).

${ }^{6}$ Ceremonia del Janli Kool presenciada por Dídac Santos-Fita los días 26/03/2011 y 03/04/2011 respectivamente en las comunidades de X-Hazil Sur y X-Pichil, Quintana Roo.
} 
esta fauna a sus cultivos (Terán y Rasmussen, 1994: 235-236). Exceptuando aquella que puede convertirse en "plaga" y perjudicar seriamente al cultivo debido a sus hábitos alimenticios (e.g. tejones, loros —Psittacidae-, tuzas), al milpero le interesa que determinada fauna silvestre, esto es, la preferida para cazar, entre en su milpa, aunque por ello "pierda" una pequeña parte de la cosecha final (venados, tepezcuintles, pavos de monte -que no perjudican tanto porque picotean los granos esparcidos en el suelo por otros animales-, faisanes, e incluso pecaríes de collar, aunque estos últimos sí puedan afectar seriamente al cultivo si el milpero no lo protege continuamente). Los más dedicados a la cacería siembran ciertas cantidades mayores de lo que saben que van a cosechar para autoconsumo y venta, y en determinadas zonas dentro de la milpa; se fijan por dónde podrían llegar los animales, para así montar los espiaderos o colocar trampas. Entonces, sin olvidar que su prioridad es cuidar su cosecha, al milpero le interesa que esta fauna silvestre se acerque a las áreas de cultivo. Se trata de buscar un balance que le permita cazar para obtener carne (proteína animal y grasa) y otros beneficios sin que la presencia del animal realmente afecte a su cosecha (Greenberg, 1992; Jorgenson, 1993; Saldivia, 1994; observación personal en trabajo de campo, 2011).

A su vez, la milpa comedero-trampa también es una práctica de manejo del hábitat, pero para facilitar expresamente la cacería, la cual es visiblemente intencional y direccionada hacia aquellas presas que son recurrentemente preferidas. El cazador siempre tiene en mente y prepara el lugar — siembra determinados cultivos agrícolas- para tener la fortuna de cazar a los animales ya mencionados. En este sentido, no difiere de la cacería en la milpa convencional o en otros espacios dentro del paisaje (Santos-Fita, Naranjo y Rangel-Salazar, 2012). De hecho, se da por sentado que el origen de la milpa comedero-trampa está en la milpa convencional, esto es, en manejar el sistema de RTQ y en "llevar" parte de sus cultivos a un espacio de índole más selvática para acostumbrar a dichos animales a que entren a comer y así tener mayores opciones de caza. El cazador prefiere que en los alrededores de su milpa comedero-trampa no haya tantos árboles silvestres dando frutos y semillas, pues le resultará más difícil que el animal entre para alimentarse del "cultivo-trampa".

La técnica de caza en una milpa comedero-trampa es la de espiar (ch'úuk; ch'uukt), esto es, subirse a un árbol y esperar en una hamaca a que llegue el animal para dispararle con una carabina (calibre .12, .16, .20) o un rifle $(.22)$. El cazador decide montar su espiadero cuando observa rastros reiterados del animal (huellas, excrementos, pelos y restos de alimentación), que se ha ido acostumbrando a llegar hasta el camote y los demás cultivos. Conocer qué especie animal es la que se acerca al área de caza, esto es, sobre sus aspectos anatómicos, biológicos, ecológicos y de comportamiento, es clave incluso a la hora de definir la altura y orientación del espiadero. Por ejemplo, venados y pecaríes pueden detectar fácilmente al cazador por el olfato, por eso el espiadero se coloca a 5-6 m del suelo, considerando la orientación en que sopla el viento (siempre hay que colocarse a contraviento) (figura 5). 


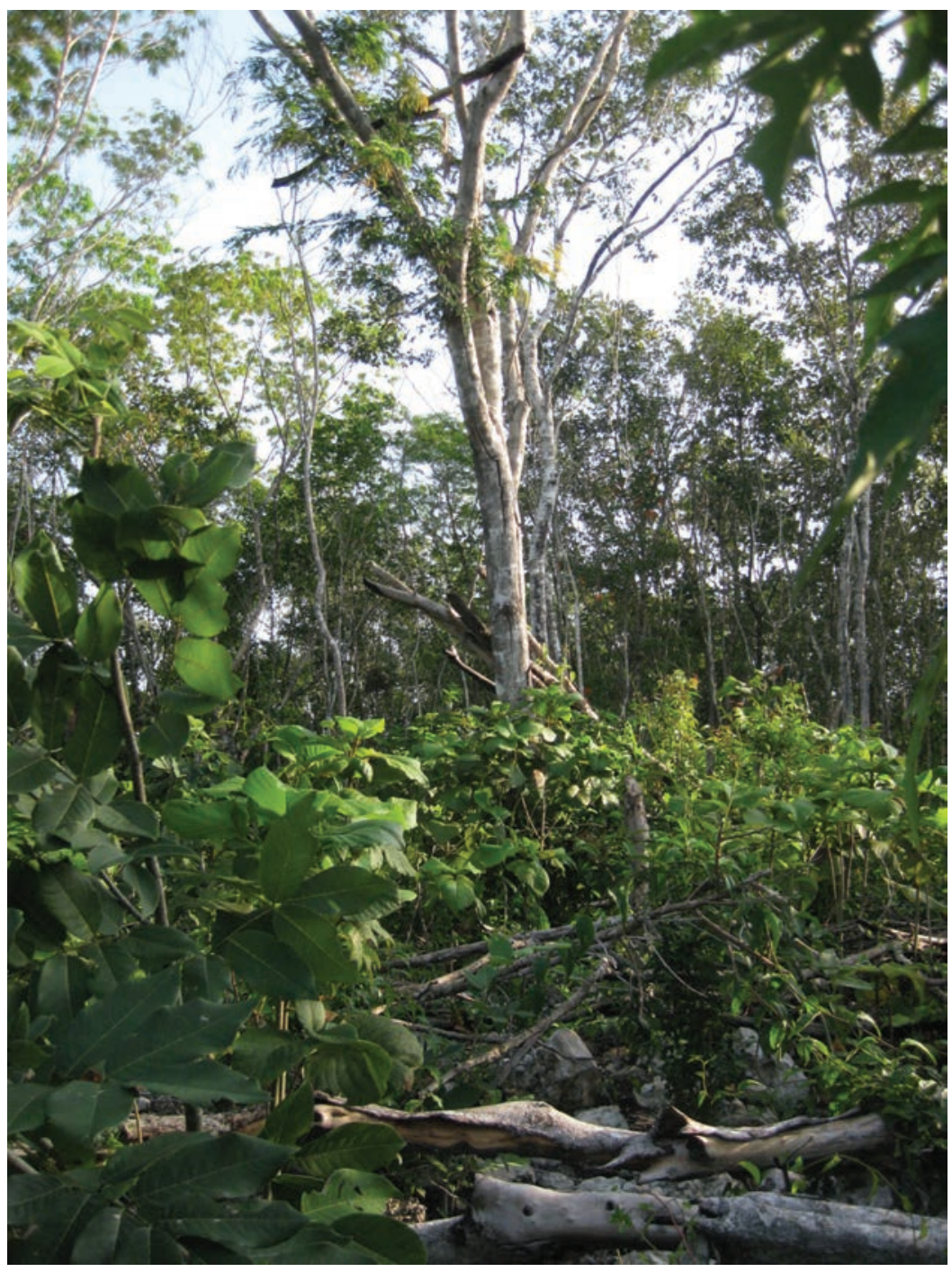

FiguRA 5. Espiadero (rama transversal) situado a 5-6 metros de altura en la milpa comedero-trampa de don "Chak Pool", de 46 años, comunidad de Señor, Quintana Roo.

Fuente: fotografía realizada por Dídac Santos-Fita (2011). 
Además, estas presas no tienen un horario estricto para llegar a comer, lo cual requiere de mayor paciencia de parte del cazador para esperarlas. Los venados y pecaríes se pueden espiar tanto en época de seca como de lluvia (que incluso favorece la entrada del venado cola blanca por los retoños). Por otro lado, la altura de espera para el tepezcuintle puede ser de menos de $1 \mathrm{~m}$, siempre y cuando el cazador no haga ningún ruido en su hamaca cuando se esté acercando el animal, sin importar el olor que desprenda o la dirección del viento. Además, este animal es de hábitos nocturnos y, por lo general, no sale de su madriguera cuando hay luz de luna. Los cazadores comentan que "quien rige [facilita] la cacería del tepezcuintlle es la luna”. El momento idóneo para ir a cazarlo es alrededor del tercer día después de la luna llena, porque en ese día únicamente transcurren dos o tres horas de oscuridad, las cuales el animal aprovecha para salir a alimentarse y regresar rápidamente a su madriguera antes de que empiece a iluminarse la noche por la luna. El cazador en esos días tiene mayores probabilidades de que se le acerque el animal en un período corto de tiempo (pocas horas), a diferencia de lo que sucede en luna nueva, cuando el animal puede llegar a cualquier hora de la noche. Asimismo, con lluvia se dificulta cazarlo, porque al estar las hojas mojadas en el suelo no se escucha cuando llega (a no ser bajo un árbol de colob —-Talisia floresii; Sapindaceae-, porque sus semillas son tan duras que el animal hace mucho ruido al roerlas).

El nombre propuesto de "milpa comedero-trampa" se tiene que entender bajo la premisa de que para los cazadores este espacio funge en realidad como una "trampa", a diferencia de una milpa convencional, aunque en ésta también pueda practicarse la cacería. Se trata de cultivar para atraer animales (de aquí su sentido de "comedero" y "trampa") y no de cultivar para autoconsumo y, secundariamente, atraer animales (como sucede en las milpas convencionales, no vistas como una estrategia directa de "trampa", a pesar de que algunos cazadores las acondicionan en parte para la llegada de animales). Considerando lo anterior, parece evidente que entender las milpas comedero-trampa puede ayudar a una mejor comprensión de la kool maya y de la técnica/sistema de RTQ, a la vez que plantea un nuevo enfoque del modelo de garden hunting.

Como la siembra interesa exclusivamente para atraer a estas presas, no para obtener cosechas, consideramos que la milpa comedero-trampa no acaba de ajustarse al modelo de "cacería en área cultivadas o huertos" (garden hunting model) propuesto inicialmente por Linares (1976), ni tampoco a las posteriores reinterpretaciones de Neusius (1996) y VanDerwarker (2006), precisamente porque siempre parten del hecho de que se siembra para autoconsumo (ver también Greenberg, 1992; Jorgenson, 1993; Saldivia, 1994; Smith, 2005).

\section{Formas de organización social, ubicación dentro del territorio y situación actual}

Otra de las particularidades de la milpa comedero-trampa es que posee un carácter enteramente individual. De hecho, al cazador que la hace no le interesa que nadie más conozca y acceda al lugar, a veces ni familiares. Varias personas en 
las comunidades saben que algunos cazadores aún las hacen, pero desconocen dónde se ubican; tampoco otros cazadores con las respectivas milpas comederotrampa conocen la localización de las milpas de los demás. Siempre se encuentran a kilómetros de distancia tanto de las zonas de milpas convencionales como de los núcleos poblacionales, sin caminos de acceso definidos ni visibles. Dos de las milpas comedero-trampa que se visitaron, en la comunidad de Señor, estaban a 14 y $18 \mathrm{~km}$ de la casa del cazador, respectivamente. La tercera, que presentaba un estado de mayor desarrollo de los cultivos (sobre todo el camote) y ya apta para usarse, se ubicaba a $4.5 \mathrm{~km}$ de la casa del cazador y a $2 \mathrm{~km}$ de su milpa convencional, en la comunidad de Uh May, Quintana Roo (figura 6).

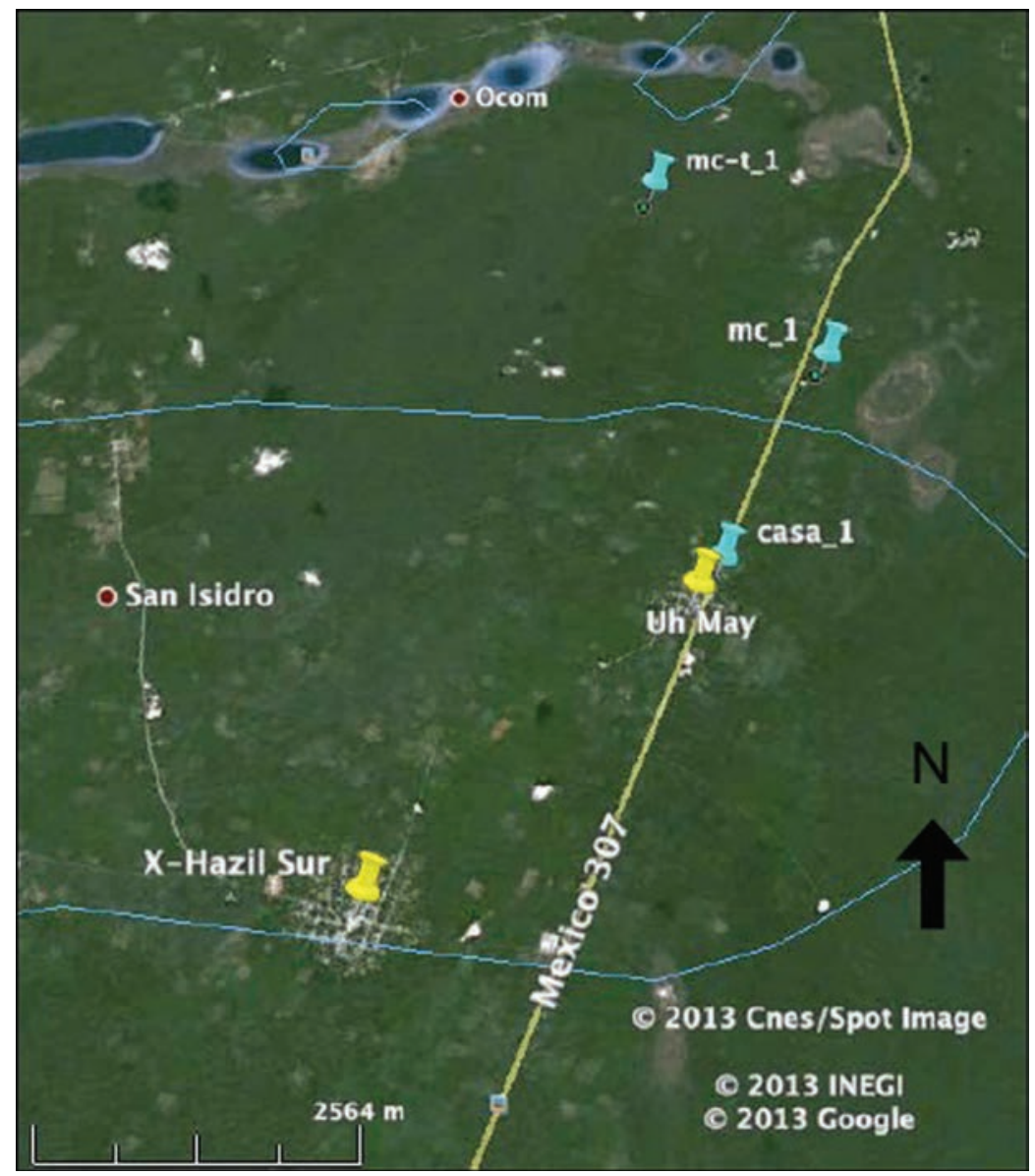

Figura 6. Ubicación de la casa, de la milpa convencional y de la milpa comedero-trampa del cazador don Facundo Puc, de 55 años, comunidad de Uh May, centro de Quintana Roo. Diseño elaborado con el software Google Earth (versión 6.1.0.5001) por Dídac Santos-Fita a partir de las coordenadas tomadas en GPS (2011). 
Este secretismo alrededor de la milpa comedero-trampa de cada cazador contrasta drásticamente con lo descrito en estudios previos en estas mismas comunidades mayas del centro de Quintana Roo y en otras del sureste de México, cuando se trata de cómo los cazadores se organizan a la hora de cazar (Jorgenson, 1993; Montiel, Arias y Dickinson, 1999; Escamilla et al., 2000; Naranjo et al., 2004; Santos-Fita, Naranjo y Rangel-Salazar, 2012). La cacería puede ser una actividad individual, en grupos reducidos (de 3-4 cazadores) o en batida (p'uuj), siendo esta última una modalidad de cacería grupal de hasta 30 participantes y normalmente con perros (Montiel, Arias y Dickinson, 1999: 45-47). Según los entrevistados, en aquellos espacios comunales como zonas de selva madura y secundaria, en la sabana, en caminos y a los márgenes de cuerpos de agua, no se considera un problema que alguien más conozca y utilice el espiadero que construyó otro cazador. Antes de reclamar por su derecho a usar su espiadero, por lo general prefieren irse a otro lado a buscar nuevos rastros de animales donde puedan colocar su hamaca para esperarlos. Asimismo, espiar implica que, si es en grupo reducido, las presas se dividen a partes iguales entre quienes participan en la caza. Sin embargo, cuando es una presa grande — venado o pecarí-, aquel que mató al animal también se queda con la cabeza, hígado, panza (la parte consumible de las tripas) y pezuñas, debido a cuestiones de creencias y prácticas rituales (Mandujano y Rico-Gray, 1991: 179; observación personal en trabajo de campo, 2011).

Ya tratándose de espacios destinados a obtener cosechas, lo que serían las milpas convencionales, el cazador debe solicitar al dueño de la milpa (el cual seguramente no suele cazar, sino lo haría él mismo) permiso para poder espiar presas dentro de ella. Al no haber ninguna regla escrita en la comunidad que lo dictamine, internamente en el grupo social se entiende - por usos y costumbres- que el cazador le tiene que dar una parte de la presa al dueño de esa milpa, en señal de agradecimiento y de favor mutuo. Sin embargo, no todos los cazadores cumplen con este requisito, ni piden permiso ni comparten al animal cazado; no hay sanción por incumplimiento, pero socialmente está mal visto. Cuando se trata de milpas comedero-trampa esto no sucede porque sus dueños, que son cazadores de los más dedicados, centran parte de sus esfuerzos en mantenerlas alejadas y ocultas al resto de los integrantes de la comunidad.

Las milpas comedero-trampa no son una práctica común actualmente, a diferencia de lo que ocurre con la milpa convencional, donde constantemente los milperos acondicionan el área para obtener cultivos agrícolas para autoconsumo, pero a la vez también algunas presas. De acuerdo a lo observado en este estudio, son muy pocos los cazadores que las continúan haciendo y las mantienen activas. Estos cazadores son de los más dedicados, que prefieren salir a buscar (kaxan) o a espiar animales a solas, casi nunca en grupos reducidos, y sólo en batida para fines religiosos de toda la comunidad (por ejemplo, conseguir carne de venado y pecarí para utilizarla en la ofrenda durante la ceremonia de petición de lluvias o Ch'áa Cháak). Todos los entrevistados señalaron que cada vez es más costoso mantener este tipo de milpas por el trabajo, la distancia y el tiempo que se 
requiere dedicarles, y no siempre dan beneficios ("Te tiene que apasionar mucho la cacería para hacer una milpita así”, don Enrique Cauich, de 51 años, comunidad de Kopchén, Quintana Roo). Además, al unísono también se afirma que las milpas convencionales ya no rinden como antes, lo que hace que la gente local se tenga que dedicar más tiempo a sus cultivos para autoconsumo (para obtener el máximo de cosecha posible) o buscar otras alternativas de subsistencia, como, por ejemplo, trabajar fuera del ámbito rural o, a nivel de comunidad, explotar recursos maderables comerciales (caoba, cedro, entre otros). Entonces, la mayoría de los pobladores han perdido el interés en las milpas comedero-trampa por las circunstancias productivas y socioeconómicas del momento.

\section{Consideraciones finales}

Las milpas comedero-trampa, al igual que las milpas convencionales y demás parches del paisaje, son una clara expresión territorial. Son espacios muy bien definidos, discontinuos y cambiantes, de acceso y apropiación del recurso faunístico, que, aunque controlados y manejados por un único individuo, a la vez tienen el reconocimiento y aceptación del resto del grupo social. Las milpas comederotrampa cumplen su cometido, desaparecen y reaparecen en otros lugares, al estar sujetas a las condicionantes ambientales que rigen todo el sistema de milpa bajo RTQ (son mucho más dinámicas que las milpas convencionales). Asimismo, se las puede considerar como una variante o subsistema dentro del sistema de producción agrícola bajo RTQ, esto es, la milpa para los mayas, dentro de la estrategia productiva y reproductiva de uso y manejo integral de la selva. Por último, y relacionado con lo anterior, las milpas comedero-trampa también representan un subsistema dentro de la actividad de cacería y del uso y manejo específico de la fauna silvestre. Cualquiera de estos enfoques sobre las milpas comedero-trampa nos habla, además, de construir socialmente el territorio y darle identidad.

Al hablar de la milpa comedero-trampa nos hemos centrado en las comunidades del centro de Quintana Roo, pobladas por mayas macehuales. Sin embargo, los entrevistados de la comunidad 20 de Noviembre (Calakmul, Campeche) mencionaron que este tipo de práctica de cacería también la realizan (o realizaban) cazadores de comunidades mayas no macehuales del actual estado de Campeche (por ejemplo en Dzibalchén, municipio de Calkiní) y del sur de Quintana Roo (como en Caobas, municipio de Othón P. Blanco). Por otro lado, los habitantes mestizos - provenientes de Veracruz, Tabasco, Campeche y, en menor cantidad, Chiapas e incluso Guatemala- de la comunidad de Nuevo Becal (Calakmul) dijeron que nunca habían oído hablar de este tipo de milpas. Esto tal vez pueda indicar que lo que aquí hemos llamado "milpa comedero-trampa" es una práctica realizada por grupos étnicos con una larga historia de ocupación del ambiente donde residen actualmente. Sus concepciones de la naturaleza y el conocimiento 
empírico que poseen de su entorno se encuentran más acentuados, con prácticas de manejo muy específicas como podrían ser las milpas comedero-trampa, que a su vez constituirían una expresión material, sociocultural y simbólica de parte de su cosmovisión.

Se requieren más estudios que ayuden a comprender mejor las milpas comedero-trampa, considerando también la conservación de la fauna silvestre y del hábitat. Falta información de otras comunidades indígenas (además de mayas) y mestizas para entender dónde se realizan o se realizaban estas milpas o una práctica de cacería semejante. Estudios de las milpas comedero-trampa desde un punto de vista histórico y socioeconómico son necesarios, así como insistir en la dimensión simbólico-religiosa de esta práctica. También será interesante conocer si existen razones históricas, familiares y sociales que determinan que un cazador haga una milpa de este tipo en ciertos espacios específicos - historia del lugar y del tipo de apropiación de los recursos naturales-, como sucede con las milpas convencionales por rumbos familiares (Terán y Rasmussen, 1994: 185187; Estrada, Bello y Velazco, 2011: 113-114). Es posible que la figura de "rancho maya" (ch'ibal; tu'x ku mentah kool, "lugar donde se hace una milpa"; Estrada et al., 2011: 68) históricamente tenga relación con la aparición de las milpas comedero-trampa, por lo menos entre comunidades mayas macehuales del centro de Quintana Roo. O por el contrario, podrían ser espacios elegidos para hacerlas porque han tenido menor intensidad de uso y manejo. Finalmente, es importante obtener datos cuantitativos del número total de milpas comedero-trampa (por ejemplo, ¿cada cuándo las activan?) y su efectividad a lo largo del tiempo (¿cuántos ejemplares por temporada logran cazar?, entre otras cuestiones) respecto al tiempo y dinero invertido, para estimar si realmente son sistemas eficaces. Se debe comprender con mayor profundidad por qué la milpa comedero-trampa es una práctica que actualmente ha caído en desuso.

\section{Agradecimientos}

Al Consejo Nacional de Ciencia y Tecnología (CONACYT) de México y a la Agencia Española de Cooperación Internacional (AECID) del Ministerio de Asuntos Exteriores y de Cooperación (MAEC) de España por las becas otorgadas (años 2009-2010 y 2011-2012, respectivamente). Dídac Santos-Fita fue becario del MAEC-AECID durante 2011-2012. Al proyecto FORDECYT-CONACYT 116306: Innovación socioambiental para el desarrollo en áreas de alta pobreza y biodiversidad de la Frontera Sur de México, por el apoyo logístico y económico en el trabajo de campo (2010-2011). A El Colegio de la Frontera Sur (ECOSUR), por su apoyo durante el desarrollo del trabajo de campo y en la fase inicial de la escritura. A la Universidad Nacional Autónoma de México (UNAM), por su apoyo económico (Oficio Núm. COHU/SIV/ SB/498/2013, beca posdoctoral, Coordinación de Humanidades) durante el período de conclusión, aceptación y publicación del presente artículo. Al Lic. Mario 
Baltazar Collí Collí, por su ayuda y corrección de los vocablos y expresiones en maya yucateco, escritos según el alfabeto aprobado en 1984 por la Comisión de Difusión del Alfabeto Maya, aún vigente. Agradecimiento especial a los habitantes de todas las comunidades donde se efectuó el trabajo de campo para el presente estudio.

\section{BIBLIOGRAFÍA}

Anderson, Eugene N.

2003 "Traditional Knowledge of plant resources", The Lowland Maya Area, pp. 623-634, A. Gómez-Pompa, M. F. Allen, S. L. Fedick y J. J. Jiménez (eds.). New York: The Haworth Press Inc.

Arce-Ibarra, Ana M.

2007 "Livelihoods, Aquatic Resources and Nonmonetary Values of Local Natural Resources in Mexico's Lowland Maya Area”, PhD thesis. Canada: Dalhousie University.

Arguielles, Luís A., Claudia Palafox, Aberto Villaseñor y Frine García

2009 Ordenamiento territorial comunitario. Ejido 20 de Noviembre, Calakmul. Campeche. México: TROPICARURAL.

Balée, William y Anne Gély

1989 "Managed Forest Succession in Amazonia: The Ka'apor Case", Resource Management in Amazonia: Indigenous Folk Strategies, pp. 129-158, D. A. Posey y W. Balée (eds.). New York: Botanical Garden.

Barrera-Marín, Alfredo, Arturo Gómez-Pompa y Carlos Vázquez-Yanes

1977 "El manejo de las selvas por los mayas: sus implicaciones silvícolas y agrícolas", Biótica, 2 (2): 47-61.

Barrera-Marín, Alfredo, Alfredo Barrera-Vázquez y Rosa María López-Franco

1976 Nomenclatura etnobotánica maya. México: Instituto Nacional de Antropología e Historia, Centro Regional Sureste (Colección Científica, 36. Etnología).

Barrera Vásquez, Alfredo et al. (eds.)

1980 Diccionario maya-español / español-maya, Mérida: Cordemex.

Bartolomé, Miguel A.

1988 La dinámica social de los mayas de Yucatán: pasado y presente de la situación colonial. México: Instituto Nacional Indigenista.

Bello, Eduardo y Erin I. J. Estrada (coords.)

2011 Cultivar el territorio maya: conocimientos y organización social en el uso de la selva. México: Fondo Institucional de Fomento Regional para el Desarrollo Científico, Tecnológico y de Innovación / Universidad Iberoamericana / El Colegio de la Frontera Sur. 
Bennett, Elizabeth L. y John G. Robinson

2000 "Hunting for Sustainability: The Star of a Syntesis", Hunting for Sustainability in Tropical Forests, pp. 499-519, J. G. Robinson y E. L. Bennett (eds.). New York: Columbia University Press.

Casas, Alejandro, Juan Luis Viveros y Javier Caballero

1994 Etnobotánica mixteca: sociedad, cultura y recursos naturales en la Montaña de Guerrero. México: Instituto Nacional Indigenista.

Coe, Michael D.

1986 Los mayas: incógnitas y realidades. México: Editorial Diana.

Comisión Nacional Forestal

2009 Ordenamiento territorial, ejido Nuevo Becal, Municipio de Calakmul, Campeche. Informe final. Chetumal: SEyBA.

Dehouve, Danièle

2008 "El venado, el maíz y el sacrificado", Cuadernos de Etnoecología, 4: 1-42. México: Instituto Nacional de Antropología e Historia.

Delfín-González, Hugo y Juan B. Chablé-Santos

2004 Uso y problemática actual de la fauna silvestre en el estado de Yucatán, México. Mérida: Secretaría para la Ecología del Gobierno del Estado de Yucatán.

Escamilla, Alfredo, Mauro Sanvicente, Miguel Sosa y Carlos Galindo-Leal

2000 "Habitat Mosaic, Wildlife Availability, and Hunting in the Tropical Forest of Calakmul, Mexico", Conservation Biology, 9 (5): 1116-1126. Washington: Society for Conservation Biology.

Estrada, Erin I. J., Eduardo Bello y Saida J. Velazco

2011 "Milpa, conocimiento local y organización social del espacio", Cultivar el territorio maya: conocimientos y organización social en el uso de la selva, pp. 99-131, E. Bello y E. I. J. Estrada (coords.). México: Fondo Institucional de Fomento Regional para el Desarrollo Científico, Tecnológico y de Innovación / Universidad Iberoamericana / El Colegio de la Frontera Sur.

Estrada, Erin I. J., Saida J. Velazco, Eduardo Bello, Pedro A. Macario, Axayácatl Segundo y Luís C. Sánchez

2011 "El rancho maya", Cultivar el territorio maya: conocimientos y organización social en el uso de la selva, pp. 67-97, E. Bello y E. I. J. Estrada (coords.). México: Fondo Institucional de Fomento Regional para el Desarrollo Científico, Tecnológico y de Innovación / Universidad Iberoamericana / El Colegio de la Frontera Sur.

Fedick, Scott L.

1996 The Managed Mosaic: Ancient Maya Agricultura and Resource Use. Salt Lake City: University of Utah Press. 
Gabriel, Marianne

2007 "El uso ritual de alcohol, tabaco, cacao e incienso en las ceremonias agrarias de los mayas yucatecos”, Estudios de Cultura Maya, XXIX: 155-184. México: Universidad Nacional Autónoma de México, Instituto de Investigaciones Filológicas, Centro de Estudios Mayas.

Garza, Mercedes de la

1984 El universo sagrado de la serpiente entre los mayas. México: Universidad Nacional Autónoma de México, Instituto de Investigaciones Filológicas, Centro de Estudios Mayas.

Gómez, Javier. A.

2009 Diccionario introductorio español-maya, maya-español. Chetumal: Universidad de Quintana Roo.

Gómez-Pompa, Arturo

1987 "On Maya Silviculture”, Mexican Studies/Estudios Mexicanos, 3 (1): 1-17. Estados Unidos: University of California Press.

2003 "Reseach Challenges for the Lowland Maya Area. An Introduction", The Lowland Maya Area, pp. 3-12, A. Gómez-Pompa, M. F. Allen, S. L. Fedick y J. J. Jiménez-Osornio (eds.). New York: Haworth Press.

Gómez-Pompa, Arturo, José S. Flores y Victoria Sosa

1987 “The 'Pet Kot': a Man-Made Tropical Forest of the Maya”, Interciencia, 12 (1): 10-15. Venezuela: Asociación Interciencia.

Greenberg, Laurie

1992 "Garden Hunting among the Yucatec Maya: a Coevolutionary History of Wildlife and Culture”, Etnoecológica, 1 (1): 23-33. México: Red de Etnología y Patrimonio Biocultural /Consejo Nacional de Ciencia y Tecnología.

Hamblin, Nancy L.

1984 Animal Use by the Cozumel Maya. Tucson: University of Arizona Press.

Hernández Xololotzi, Efraím

1981 "Prácticas agrícolas", La milpa entre los mayas de Yucatán, pp. 45-73, L. Varguez Pasos (ed.). Mérida: Ediciones de la Universidad Autónoma de Yucatán.

Hernández Xolocotzi, Efraím, Eduardo Bello y Samuel Levy (coords.)

1995 La milpa en Yucatán: un sistema agrícola tradicional. México: Colegio de Postgraduados, 2 tomos.

Jorgenson, Jeffrey P.

1993 "Gardens, Wildlife Densities, and Subsistence Hunting by Maya Indians in Quintana Roo, Mexico”, PhD thesis. Gainesville: University of Florida.

Landa, fray Diego de

1994 Relación de las cosas de Yucatán, María del Carmen León Cázares (est. prel., 
cronol. y rev. del texto). México: Consejo Nacional para la Cultura y las Artes (Cien de México).

Llanes-Pasos, Eleuterio

1993 Cuentos de cazadores. Chetumal: Gobierno del Estado de Quintana Roo, Fondo de Publicaciones y Ediciones.

Linares, Olga $\mathrm{F}$.

1976 "Garden Hunting in the American Tropics", Human Ecology, 4 (4): 331-349. Nueva York: Springer.

Lope-Alzina, Diana G. y Patricia L. Howard

2012 "The Structure, Composition and Functions of Homegardens: Focus on the Yucatan Peninsula”, Etnoecológica, 9 (1): 17-41. México: Red de Etnología y Patrimonio Biocultural / Consejo Nacional de Ciencia y Tecnología.

Love, Bruce y Eduardo Peráza

1984 "A Yucatec Maya Agricultural Ceremony", Estudios de Cultura Maya, XV: 251307. México: Universidad Nacional Autónoma de México, Instituto de Investigaciones Filológicas, Centro de Estudios Mayas.

Macario, Pedro A. y Luis C. Sánchez

2011 "Recolección de plantas de uso forestal tradicional y extracción forestal comercial en una comunidad maya del centro de Quintana Roo", Cultivar el territorio maya: conocimientos y organización social en el uso de la selva, pp. 213-236, E. Bello y E. I. J. Estrada (coords.). México: Fondo Institucional de Fomento Regional para el Desarrollo Científico, Tecnológico y de Innovación / Universidad Iberoamericana / El Colegio de la Frontera Sur.

Mandujano, Salvador y Víctor Rico-Gray

1991 "Hunting, Use, and Knowledge of the Biology of the White-Tailed Deer (Odocoileus virginianus Hays) by the Maya of Central Yucatan, Mexico", Journal of Ethnobiology, 11 (2): 175-183. Gainsville, Florida: Centre for International Ethnomedicinal Education and Research.

Mariaca, Ramón, Alba González-Jácome y Luís Manuel Arias

2010 El huerto maya yucateco en el siglo XVI. México: El Colegio de la Frontera Sur / Instituto Politécnico Nacional, Centro de Investigación y de Estudios Avanzados / Consejo Nacional de Ciencia y Tecnología, Fondos Mixtos de Fomento a la Investigación Científica y Tecnológica / Universidad Intercultural Maya de Quintana Roo / Consejo de Ciencia, Innovación y Tecnología del Estado de Yucatán.

Marion, Marie-Odile

1994 Identidad y ritualidad entre los mayas. México: Instituto Nacional Indigenista / Secretaría de Desarrollo Social. 
Montiel, Salvador, Luis M. Arias y Federico Dickinson

1999 "La cacería tradicional en el norte de Yucatán: una práctica comunitaria", Geografía Agrícola, 29: 42-52. México: Universidad Autónoma de Chapingo.

Montolíu, María

1976 "Algunos aspectos del venado en la religión de los mayas de Yucatán", Estudios de Cultura Maya, X: 149-172. México: Universidad Nacional Autónoma de México, Instituto de Investigaciones Filológicas, Centro de Estudios Mayas.

Naranjo, Eduardo J., Michelle M. Guerra, Richard E. Bodmer y Jorge E. Bolaños

2004 "Subsistence Hunting by Three Ethnic Groups of the Lacandon Forest, Mexico", Journal of Ethnobiology, 24 (2): 233-253. Gainsville, Florida: Centre for International Ethnomedicinal Education and Research.

Naughton-Treves, Lisa

2002 "Wild Animals in the Garden: Conserving Wildlife in Amazonian Agroecosystems", Annals of the American Association of Geographers, 92 (3): 488-506. Washington: Association of America Geographers.

Neusius, Sarah W.

1996 "Game Procurement among Temperate Horticulturists: The Case for Garden Hunting by the Dolores Anasazi”, Case Studies in Environmental Archaeology, pp. 273-288, E. J. Reitz, L. A. Newsom y S. J. Scudder (eds.). New York: Plenum Press.

Pérez-Toro, Augusto

1945 “La agricultura milpera de los mayas de Yucatán”, Enciclopedia Yucatenense de Yucatán, tomo VI, pp. 173-204. México: Gobierno de Yucatán.

Porter-Bolland, Luciana

2003 "Apicultura y paisaje maya en La Montaña, Campeche, México", Mexican Studies / Estudios Mexicanos, 19: 303-330. Estados Unidos: University of California Press.

Programa de Manejo de la Reserva de la Biosfera Sian Ka'an

1996 México: Instituto Nacional de Ecología

Programa de Manejo de la Reserva de la Biosfera Calakmul. 2000 México: Instituto Nacional de Ecología.

Ramírez-Barajas, Pablo J., Nuria Torrescano-Valle, Alejandro Tecpa-Jiménez y José VázquezRodríguez

2001 "Importancia y uso del entorno natural en una comunidad Maya (Petcacab, Quintana Roo, México)”, TIP Revista Especializada en Ciencias Químico-Biológicas, 4: 61-71. México: Universidad Nacional Autónoma de México, Facultad de Estudios Superiores Zaragoza, División de Estudios de Posgrado e Investigaciones. 
Reed, Nelson A.

1987 La Guerra de Castas de Yucatán, México: Era.

Relaciones Histórico-Geográficas de la Gobernación de Yucatán (Mérida, Valladolid, Tabasco)

1983 Edición preparada por Mercedes de la Garza y colaboradores. Texto facsimiliar y nuevas transcripciones paleográficas, 2 vols.: I: 445 pp.; II: 494 pp. y 2 mapas. México: Universidad Nacional Autónoma de México.

Remmers, G. G. A. y H. de Koeijer

1992 “The T'OLCHE': a Maya System of Communally Managed Forest Belts: the Causes and Consequences of its Disappearance", Agroforestry Systems, 18: 149-177. Holanda: Springer.

Rojas-Rabiela, Teresa

1991 "Agricultura prehispánica", La agricultura en tierras mexicanas desde sus orígenes hasta nuestros días, pp. 15-119, T. Rojas-Rabiela (coord.). México: Los Noventa / Consejo Nacional para la Cultura y las Artes / Grijalbo.

Saldivia, Tereso

1994 "Estudio sobre la relación entre la fauna silvestre y la milpa en ejidos forestales de Quintana Roo", Memorias del XII Simposio sobre Fauna Silvestre, pp. 496-512. México: Universidad Nacional Autónoma de México.

Sanabria, Olga L.

1986 El uso y manejo forestal en la comunidad de Xul, en el sur de Yucatán. México: Universidad Autónoma de Yucatán.

Sandoval, Carlos A.

1996 Investigación cualitativa. Bogotá: Instituto Colombiano para el Fomento de la Educación Superior, Programa de Especialización en Teoría, Métodos y Técnicas de Investigación Social (Módulo 4).

Santos-Fita, Dídac

2013 "Cacería de subsistencia, manejo y conservación de fauna silvestre en comunidades rurales de la Península de Yucatán, México", tesis de doctorado en Ciencias en Ecología y Desarrollo Sustentable. San Cristóbal de Las Casas: El Colegio de la Frontera Sur.

Santos-Fita, Dídac, Eduardo J. Naranjo y José Luis Rangel-Salazar

2012 "Wildlife Uses and Hunting Patterns in Rural Communities of the Yucatan Peninsula, Mexico", Journal of Ethnobiology and Ethomedicine, 8 (38): 1-18. Reino Unido: BioMed Central.

Smith, Derek A.

2005 "Garden Game: Shifting Cultivation, Indigenous Hunting and Wildlife Ecology in Western Panama”, Human Ecology, 33: 505-537. Nueva York: Springer. 
Speth, John D. y Susan L. Scott

1989 "Horticulture and Large-Mammal Hunting: The Role of Resource Depletion and the Constrains of Labor", Farmes as Hunters: The Implications of Sedentism, pp. 71-79, S. Kent (ed.). New York: Cambridge University Press.

Terán, Silvia y Christian H. Rasmussen

$1994 \quad$ La milpa de los mayas. La agricultura de los mayas prehispánicos y actuales en el Noreste de Yucatán. México: Centro de Investigación Científica de Yucatán / Gobierno de Dinamarca.

Toledo, Víctor M., Narciso Barrera-Bassols, Eduardo García-Frapolli y Pablo Alarcón-Chaires 2008 "Uso múltiple y biodiversidad entre los mayas yucatecos (México)", Interciencia, 33 (5): 345-352. Venezuela: Asociación Interciencia.

VanDerwarker, Amber M.

2006 Farming, Hunting and Fishing in the Olmec Word. Austin: University of Texas Press.

Valverde, Nicolás M.

1976 "Evaluación agronómica de un sistema de producción con maíz (Zea mays L.) y camote (Ipomoea batatas (L.) Lam.)", tesis para optar al grado de Magister Scientiae. Costa Rica: Centro Agronómico Tropical de Investigación y Enseñanza, Turrialba.

Villa Rojas, Alfonso

1987 Los elegidos de Dios: etnografía de los mayas de Quintana Roo. México: Instituto Nacional Indigenista (Antropología Social, 56).

Zizumbo, Daniel, Christian H. Rasmussen, Luis M. Arias y Silvia Terán (eds.)

1992 La modernización de la milpa en Yucatán: utopía o realidad. México / Dinamarca: Centro de Investigación Científica de Yucatán / Ministerio de Asuntos Exteriores de Dinamarca. 